See discussions, stats, and author profiles for this publication at: https://www.researchgate.net/publication/325450552

\title{
Where Power Resides in Committees
}

Preprint · May 2018

CITATIONS

0

2 authors:

(2) Georg D. Granic

Erasmus University Rotterdam

15 PUBLICATIONS 42 CITATIONS

SEE PROFILE
READS

66

20. Alexander K. Wagner

University of Vienna

15 PUBLICATIONS 111 CITATIONS

SEE PROFILE 


\title{
Where Power Resides in Committees*
}

\author{
Georg D. Granic ${ }^{\diamond} \quad$ Alexander K. Wagner ${ }^{\star}$
}

February 18, 2019

Forthcoming in The Leadership Quarterly

\begin{abstract}
The power to control decisions is rarely distributed equally in committees. In a small voting committee, in which members have conflicting interests, we study how the decision right to break ties (formal power) translates into effective control over outcomes (real power). Two controlled experiments show that the level of real power held by the chair is larger than predicted by rational-choice theory. We also provide causal evidence that the legitimacy, but not the salience, of holding formal tie-breaking power affects voting behavior and thus the distribution of real power in the committee. Attitudinal measures related to the perceived attractiveness of the decision right to break ties exhibit a strong asymmetry between the one holding the decision right and those who do not.
\end{abstract}

* We thank Carlos Alós-Ferrer, Steven J. Brams, John Duffy, Holger Herz, Dennis C. Mueller, Karine Van der Straeten, Juha Tolvanen, James Tremewan, Jean-Robert Tyran, and especially the editor as well as two anonymous referees for helpful comments. We also thank seminar participants at the University of Cologne, Erasmus University Rotterdam, University of Vienna, and conference participants at the 9th AEW in Barcelona, the 2nd IMEBESS in Toulouse, the FPRWS Workshop in Vienna, the NOeG-SEA Conference in Bratislava, the GAMES 2016 in Maastricht, and the 11th NCBEE in Oslo for useful comments. The first draft was written while Granić was visiting New York University, whose hospitality is gratefully acknowledged. Granić also gratefully acknowledges financial support from the German Research Foundation (DFG) through research project AL-1169/2-1 and from the Netherlands Organisation for Scientific Research through VIDI project 452-13-013. Wagner gratefully acknowledges support from the Heinrich Graf Hardegg'sche Stiftung as well as financial support from the German Research Foundation (DFG) through research fellowships WA3559/1-1 and WA3559/2-1.

$\diamond$ Department of Applied Economics, Erasmus School of Economics, Erasmus University Rotterdam, PO Box 1739, 3000 DR Rotterdam, The Netherlands. Email: granic@ese.eur.nl

- Vienna Center for Experimental Economics and Department of Economics, University of Vienna, OskarMorgenstern-Platz 1, A-1090 Vienna, Austria. Email: alexander.k.wagner@univie.ac.at 


\section{Introduction}

Casual observation suggests that many organizations consist of a small number of leaders, who exercise their decision power relentlessly, and many lower-ranking others, whose job it is to simply carry out these decisions. Whereas this view is certainly accurate for some forms of social interaction, however, it neglects many important guises in which power manifests itself in organizations (Anderson and Brion, 2014; Arrow, 1974; Flynn et al., 2011; Simon, 1951; Sturm and Antonakis, 2015). Specifically, quite often those who hold the formal decision right are not the ones who possess effective control over the outcomes in organizations.

The potential discrepancy between the right to control decisions (formal power) and the effective control over outcomes (real power) in strategic situations, as well as covariates that moderate this trade-off, are the main subjects of this article. We study the effects of power in the context of small committees that reach decisions through voting, a common practice in both public and private organizations such as juries at court or boards of directors. For example, monetary policy boards in central banks began switching from discretionary decision making by a single individual to committee decision making in the 1990s (Blinder, 2004). About ten years later, 79 out of 88 surveyed monetary policy boards had moved to committee decision making (see Blinder, 2007).

In general, employing committees for decision-making is motivated by two distinct reasons. First, voting committees can be used to aggregate committee member information, if their preferences are aligned. Second, voting committees can be used to reconcile conflicting interests of members. Furthermore, beyond the effects of preference structure, the distribution of power in a committee can also be affected by many other factors including (in)formal rules, asymmetries among members, and differences in leadership styles. In this paper, we consider the case of conflict in a committee and investigate the consequences of a small asymmetry in one member's formal voting power on committee voting behavior and outcomes.

Our main concepts, formal and real power, can be approached intuitively as follows. Formal power in a committee is an explicit decision right, precisely specifying its scope (power 
over what) and extent (when can power be exercised). ${ }^{1}$ The real power of a committee member, in contrast, captures the effective control over committee decisions and can be assessed by the degree to which the collective decision is aligned with the preferences (over the set of all possible outcomes) of a committee member. ${ }^{2}$ Final decisions reached in such committees depend potentially on the votes of all members. Because members have conflicting views about which is the most attractive alternative to implement, our setting gives rise to strategic considerations, which, in turn, open up the scope for a potential mismatch between formal power and real power. ${ }^{3}$

More specifically, we theoretically and experimentally investigate the effects of formal tiebreaking power on behavior as well as on committee members' perceptions of power as an important antecedent of behavior. The small asymmetry induced by the decision right to break ties is not only of theoretical interest, but is prevalent in many real-world committees. In our canonical setting, the committee decides by simple plurality voting which of the three possible alternatives to implement. Each of the three committee members holds a regular vote and the regular vote of one member, referred to as the chair of the committee, serves as the casting vote in case of a tie. ${ }^{4}$ We evaluate observed behavior in controlled laboratory experiments against the rational-choice benchmark (Farquharson, 1969). The theoretical predictions are derived under the assumption that each member acts in a fully rational and self-interested manner and expects all other members to do so as well (see Section 2 for details).

\footnotetext{
1 The presiding chair of a committee may, for example, be given the formal power to adjourn the committee (scope) if a certain quorum is not met (extent). See Section 2.1 for a precise definition of formal and real power and a discussion of their relation to other definitions of power in the organizational literature.

2 Consider, for instance, a hiring committee in which members have different preferences over the set of available applicants. The real power of a committee member is then captured by how often her most preferred applicant is actually hired.

3 The relationship between formal and real power, and its dependence on the form of strategic interaction, is itself not new and has been addressed long before its theoretical formalization. In his seminal treatise on civil obedience, de la Boétie (1975), a 16th century French philosopher (and close friend of Michel de Montaigne), already combines elements of psychological perceptions of power with arguments of coordination to explain why people obey even tyrants in government.

4 The precise type of tie-breaking rule we consider is used in many small-sized committees, including various Constitutional Courts in Europe (e.g., France, Italy, Spain), the International Court of Justice of the United Nations in The Hague, and committees of the Swiss parliament (National Council), among others.
} 
In contrast to conceptions of power typically used in organizational theory, the tie-breaking power of the chair implies zero real power in this case. The intuition behind this result is straightforward. The asymmetric tie-breaking power of the chair creates strong incentives for all non-power holders to vote for the chair's least-preferred alternative; non-power holders implement this alternative, in equilibrium, with a 2-to-1 majority through tacitly coordinating their votes against the chair's preferred alternative.

We conduct two independent experiments to establish the existence of the real power of the chair and isolate important psychological factors that can explain deviations from the rational-choice prediction. Results show that the chair's real power is substantially higher than predicted by rational-choice theory and is mainly associated with one regular committee member siding with the formal power holder. Our treatment variation in Experiment 1 provides causal evidence that holding tie-breaking power legitimately increases the real power of the chair in the committee in the short run. The treatment effect supports previous findings, which have shown that legitimacy is a vital element of how people react to formal power in other social contexts (e.g. Kelman, 1958; Milgram, 1963; Silverman et al., 2014; Suchman, 1995; Tyler, 2006). Specifically, legitimate power of the chair sways one regular member, against her monetary incentives, into choosing the chair's preferred alternative more often than if tie-breaking power is allocated randomly. The direction of the treatment effect is consistent with compliant and conformist behavior of regular members as predicted by, among others, the inhibition theory of power (Cialdini and Goldstein, 2004; Keltner et al., 2003; Lammers et al., 2008) and the concepts of legitimate and referent power (French and Raven, 1968).

In Experiment 2, we study whether the labeling (in the sense of salience) of the chair position has, in addition to the asymmetric rule power, a causal effect on the real power of the chair and on how tie-breaking power is perceived in the committee. Results show that the labeling of the chair role has no effect on either voting behavior or the stated attractiveness of the chair role. Elicited measures of the attractiveness of the chair position, however, reveal that committee members seem to learn about the actual attractiveness of holding tie-breaking 
power in the committee differently over time. Whereas regular members rationally adjust their assessment of real power over time in accordance with their experience, chairs only partially take this information into consideration with respect to their assessment of their own role, and also do not revise their view about regular members over time. In this sense, elicited measures of attractiveness are consistent with an emerging body of work on the non-instrumental value of decision rights (Bartling et al., 2014; Fehr et al., 2013).

Our study is one of the first to provide insight into the internal workings of decision making in committees when formal power induces small rule asymmetries among members. We contribute to the existing literature in several ways. To begin, while previous experimental studies on small-group decision making focus mostly on the effects of power asymmetries on outcome efficiency (e.g. Hastie and Kameda, 2005; Kameda, 1991; Mannix et al., 1989; Mannix, 1993; Thompson et al., 1988), in our setting, all final decisions yield the same level of efficiency and only differ in the distribution of payoffs among members. Methodologically, we contribute to a rigorous causal analysis of power in committees and some of its important determinants, using controlled laboratory experiments. A main advantage of our stylized setup is that it allows for a precise definition and identification of power. It thereby also circumvents possible experimenter demand effects, related to power manipulations, that employ priming interventions (cf. Zizzo, 2010).

We also add to the emerging literature on evidence-based assessments of power in committees, and of behavior in committees more generally. Whereas there exists much anecdotal evidence regarding the power of chairs in committees, rigorous causal evidence has been scarce in the literature. One reason for this dearth lies in the difficulty in establishing reliable causal evidence of chair power using observational data from real-world committees because of issues of endogeneity, e.g., selection bias (Antonakis et al., 2010; Zehnder et al., 2017). A notable exception in this respect is the work by Berry and Fowler $(2015,2018)$, which provides strong empirical evidence on the influential position of chairs using observational data from congressional committees in the United States. ${ }^{5}$ With regards to experimental evidence, it has been

\footnotetext{
5 Berry and Fowler (2018) show empirically that the position of the chair is clearly desirable in legislative
} 
unclear how tie-breaking power influences committee decision making. Blinder and Morgan (2005, 2008), for instance, study how leadership in monetary policy boards affects decision making in a common-interest setting when the chair holds tie-breaking power. They find no evidence of a leadership effect in general, and no effect of tie-breaking power in particular. ${ }^{6}$ Finally, note that effects of asymmetric decision power more generally have also been studied in the context of delegating decision rights in organizational economics, both theoretically (Aghion and Tirole, 1997; Grossman and Hart, 1986; Hart and Moore, 1990; Simon, 1951) and experimentally (Bartling et al., 2014; Dominguez-Martinez et al., 2014; Fehr et al., 2013).

The remainder of this paper is organized as follows. Section 2 presents our working definition of power, derives the theoretical predictions in the committee game under fullyrational behavior, and then states the main experimental hypotheses regarding committee behavior. Sections 3 and 4 present the design and results of Experiment 1 (legitimacy of chair) and Experiment 2 (labeling of chair position), respectively. Finally, section 5 discusses the robustness of the results and the implications of our findings for future research.

\section{Theoretical background and hypotheses}

Before presenting our committee voting framework, its rational-choice benchmark predictions, and the main experimental hypotheses, we develop our working definition of power and discuss its relation to existing definitions in the organizational literature.

\subsection{Formal and real power of the chair}

Broadly speaking, power is defined as "the discretion and the means to asymmetrically enforce one's will over others" (Sturm and Antonakis, 2015, p.139). ${ }^{7}$ Along with those holding it,

committees and provide an overview of the empirical literature.

6 In their study, committees perform about the same with or without a leader. Note, however, that the preferences structure of common interests studied in these papers is fundamentally different from our setting, in which members have conflicting preferences over the best alternative to implement. To ensure success in either of these two situations, leaders will require very different strategies.

7 The above definition encompasses other definitions that characterize power as asymmetric control over material or immaterial resources (Bartlett, 1989; Pfeffer, 1981; Russel, 1938; Weber, 1978a). Anderson and 
power has long been the subject of public attention and scientific scrutiny. Theories of power, advanced in social psychology, sociology, political science, management, and economics, have generated important insights into the nature of power as well as its origins and consequences.

A common theme in organizational research on power is the use of psychological manipulations to test their psychological or behavioral consequences on the powerful or the powerless (e.g. Galinsky and Mussweiler, 2001; Galinsky et al., 2003; Magee et al., 2007). We follow this general approach and manipulate the perception of the chair's formal power, through different treatment variations, to test its causal impact on the chair's influence on decisions made in the committee. Our treatment manipulations, as well as our measures of power, are embedded structurally in a setting of strategic decision making. It is well known that the specific type of strategic setting has a strong influence on behavior (e.g. Camerer, 2003), and, in our case, on the scope of a member's effective control over outcomes in the committee. In our setting, committee members have strongly conflicting interests and, hence, strong incentives to act in their self-interest. For these reasons, our definitions of formal and real power take the underlying strategic interdependencies carefully into account.

Definition (Formal and real power). The decision right to break ties, referred to as formal power, is held by the chair of the committee. We define the real power of the chair as the effective influence on the decision made by the voting committee, or, more specifically, the frequency with which the chair's most-preferred alternative is chosen as the outcome.

In the above definition, formal power of the chair is a non-contractible decision right (Baker et al., 1999). ${ }^{8}$ Real power is measured at the outcome level, and therefore measures the de facto influence of the chair on the committee decision. The distinction between holding Brion (2014) and Sturm and Antonakis (2015) provide comprehensive and up-to-date reviews of the concept of power relevant to decision making in organizations.

8 More generally, note that power asymmetries are generated in strategic environments not only through differences in decision rights but also by differences in the available actions, the available payoffs, or the timing of moves in strategic environments. Thompson et al. (1988) and Mannix et al. (1989), for example, study the effects of asymmetric outside options in a negotiation context in which some members of a group receive higher payoffs than other members if the group fails to reach a consensus decision. In our setting, it is the additional decision right of the chair to break ties that establishes the asymmetry between committee members. 
the formal decision right and real influence over outcomes is most closely related to Aghion and Tirole (1997) who consider a principal facing the challenge to optimally delegate her decision right to an agent. Optimal delegation of 'real authority' to the agent is shown to depend on the degree of asymmetric information and the alignment of interests between contracting parties. Importantly, the principal always holds the right to decide, called 'formal authority', which implies that the mapping from formal power into real power is always under the control of the principal. In contrast to the delegation literature (e.g. Aghion and Tirole, 1997; Grossman and Hart, 1986; Hart and Moore, 1990), it is the behavior of all committee members that determines whether the chair can wield her formal tie-breaking power to her advantage or not. In our setting, there is an asymmetry between committee members, which is reflected by the chair's discretion to determine the outcome in the committee. The chair's formal decision right to break ties is, however, not unconditional but rather only applicable if voting in the committee has reached a tie. In this sense, the formal tie-breaking power of the chair represents a "source of potential influence" (Anderson and Brion, 2014, p.69); its realization, however, depends on the voting behavior of all members in the committee.

\subsection{Rational-choice predictions of committee behavior}

Next, we present the game-theoretic predictions regarding voting behavior and outcomes in the committee. The committee voting model serves in both experiments as the strategic environment in which committee members interact with each other. The committee setup, originally studied by Farquharson (1969), consists of three members who we refer to as the chair, player 2, and player 3. The committee decides to implement one of three available alternatives, say $A, B$, or $C$. Members' preferences over alternatives are publicly known and represent a situation of conflict. Each member favors a distinct alternative: $A \succ B \succ C$ for the chair, $C \succ A \succ B$ for player 2, and $B \succ C \succ A$ for player 3, with $\succ$ denoting the strict preference relation, as summarized in Table 1. Members vote simultaneously and independently for one of the alternatives. The winner is determined by plurality voting with one important qualification: in case of a tie among alternatives, the tie is broken by the 
alternative the chair has voted for with her regular vote. The asymmetry in tie-breaking power seems to give the chair an edge over the other two members, referred to as regular members. We show next why this is not necessarily the case and how strategic incentives can render the chair's formal power ineffective.

To derive the rational-choice predictions of behavior in the committee, we assume that rational committee members use voting strategies that are weakly dominant, i.e., strategies that are never worse and are sometimes better than other strategies. We also assume that they successively eliminate weakly dominated strategies. Consider the committee structure in Table 1 from the perspective of the chair. For her, two different types of situations are relevant. First, the other two members vote for the same alternative, in which case the committee decision is fixed and the chair's vote has no influence on the final outcome (and hence no real power). Second, the other two members vote for distinct alternatives. In this case, the chair's vote is decisive and whatever she votes for is implemented, either by creating a three-way tie among the alternatives, or a 2-to-1 victory for the alternative the chair voted for. For the chair, voting for $A$ is, thus, weakly dominant. An analogous argument shows that, if player 2 anticipates the chair's behavior, she is left with only one dominant strategy: to vote for $C$. In turn, player 3 faces the decision to either vote for $C$ herself and implement $C$ with a 2-to-1 majority, or not to vote for $C$, which implements $A$ for sure. Given that she strictly prefers $C$ over $A$, voting $C$ dominates not voting for $C$. The committee thus reaches the decision to implement the chair's least preferred alternative $C$, as player 2 and player 3 vote for $C$ and the chair votes for $A$.

For readers familiar with game theory, the above behavioral prediction can also be stated more formally. It is immediately clear that there are five strategy profiles that constitute purestrategy Nash equilibria (NE) in the one-shot game, given the preference profile in Table 1. These are $(A, A, A),(B, B, B),(C, C, C),(A, A, B)$, and $(A, C, C)$, with the first, second, and third entry in a strategy profile denoting the vote of the chair, player 2 , and player 3 , respectively. ${ }^{9}$ Note that it is common in the voting literature to apply refinements to the NE

\footnotetext{
9 Informally, a situation in which no member has an incentive to change her vote unilaterally, that is, given
} 
solution concept because issues with multiple equilibria are bound to ensue. ${ }^{10}$ We follow two requirements based on weak dominance to reduce the number of NE, namely: elimination of weakly dominated strategies (WDS) and iterated elimination of weakly dominated strategies (IEWDS), see Moulin (1979), Kohlberg and Mertens (1986), or Dhillon and Lockwood (2004). First, we eliminate the weakly dominated strategies for all members simultaneously. This yields a new, reduced game. We then apply the elimination of weakly dominated strategies to the reduced game and repeat this process iteratively until no further reduction of the game is possible. In the game we consider, voting for alternative $B$ (respectively $A$ ) is weakly dominated for player 2 (respectively player 3 ). For the chair, voting for $A$ is the only weakly undominated strategy. This eliminates the three unanimous NE: $(A, A, A),(B, B, B)$, and $(C, C, C)$. In the second round of the elimination process, voting for alternative $A(B)$ becomes iteratively weakly dominated for player 2 (player 3 ). The second round thus eliminates the NE $(A, A, B)$ and no further reduction of the game form is possible. Applying the concept of IEWDS, the only profile surviving is $(A, C, C)$. This result is known as the 'paradox of the chairman's vote' (Farquharson, 1969, p.51) because it leads to the chair's least-preferred alternative being implemented if committee members act rationally.

The rational-choice analysis illustrates why voting committees in general, and the structure we consider in particular, offer an ideal framework for investigating potential discrepancies between formal and real power. Let us assume that all members vote sincerely. In this case, all committee members neglect strategic motives and simply vote for their mostthat the other players' votes remain fixed, constitutes a Nash equilibrium in pure strategies in the committee voting game. For example, consider the Nash equilibrium $(A, C, C)$ in Table 1 in which the committee implements alternative $C$. Player 3 has no incentive to choose any alternative other than $C$, given that the chair and player 2 voted for $A$ and $C$, respectively. The reason is the following. If player 3 votes for $A$ instead of $C$, outcome $A$, which is less preferred than outcome $C$ by player 3 , will be implemented. She has hence no incentive to deviate from $C$ to $A$. If player 3 instead changes her vote from $C$ to $B$, then a tie occurs and the chair's tie-breaking power will be implement $A$. Consequently, player 3 cannot do better than to vote for $C$, given that the other two members vote for $A$ and $C$, respectively. Applying the same reasoning, one can show that neither the chair nor player 2 has an incentive to change their vote, which establishes that the strategy profile $(A, C, C)$ is a Nash equilibrium.

10 For example, with $N \geq 3$ voters and plurality voting, all unanimous voting profiles constitute a Nash equilibria of the game, irrespective of the tie-breaking rule. 
Table 1: Preference profile and Nash equilibria in the committee game.

\begin{tabular}{lccccccc}
\hline & & \multicolumn{5}{c}{ Nash equilibria } \\
\cline { 3 - 7 } & Preference profile & \multicolumn{4}{c}{ Unanimous } & WDS & IEWDS \\
\hline Chair & $A \succ B \succ C$ & $A$ & $B$ & $C$ & $A$ & $A$ & $A$ \\
Player 2 & $C \succ A \succ B$ & $A$ & $B$ & $C$ & $A$ & $C$ & $C$ \\
Player 3 & $B \succ C \succ A$ & $A$ & $B$ & $C$ & $B$ & $C$ & $C$ \\
\hline
\end{tabular}

preferred alternative. This outcome yields the voting profile $(A, C, B)$, a three-way tie. The chair's vote of $A$ is transformed into a casting vote, breaks the tie, and the committee implements $A$. Formal power in this case implies absolute real power as the committee implements the chair's most referred alternative. This result is in stark contrast to the rational-choice prediction derived above, which implies zero real power of the chair. Another possibility to consider is the case of random behavior, i.e., each member chooses her alternative based on a uniform probability distribution. The chair's real power would then simply be $1 / 3$. These different examples illustrate the flexibility of our simple voting framework, which spans the entire spectrum of real power and allows us to associate real power with underlying individual behavior.

\subsection{Behavioral hypotheses}

The rational-choice predictions presented in Section 2.2 provide the theoretical benchmark for committee member behavior in the experiment. This allows us to directly state our theorydriven hypothesis regarding committee behavior, which is then tested against observed levels of real power in each of the experiments.

Hypothesis 1 (Real power of chair). The rational-choice model in Section 2.2 predicts that the chair's preferred alternative A will be implemented in the committee with zero probability. This outcome implies that the chair holds no real power in the committee, i.e., no effective control over outcomes. 
The rational-choice predictions highlight several important features of our committee framework. Purely self-interested regular members seeking to maximize their preferences over alternatives are offered strong incentives to coordinate against the power holder. The chair, on the other hand, has no means with which to punish members and no reward mechanism with which to encourage their cooperation. The structure of the committee game also excludes any possibility of communication, so the chair cannot coax regular members into voting in her favor. Systematic deviations from the rational-choice benchmark can thus only be due to errors in decision making or psychological factors. Within our setting, the latter are associated with the perception of formal power, which can trigger psychological motives to side with power holders. Although our experiments are not designed to discriminate between alternative explanations for deviations from the rational-choice benchmark, our committee setup allows for a clean identification of the presence of psychological motives and, therefore, for establishing their relevance in a highly competitive setting in which deferring to the powerful is associated with negative material consequences for regular members.

Irrespective of possible deviations from the rational-choice benchmark predictions tested in Hypothesis 1, our treatment manipulations measure the causal effect of chair legitimacy (Hypothesis 2) and the labeling of chair position (Hypothesis 3) on the real power of the chair in the committee. In other words, the empirically tested treatment effects in a given experiment can be thought of as quantifying the relative deviation from the observed baseline (control) and from which conjectures about relevant psychological theories of committee behavior can be drawn.

Treatments in Experiment 1 vary how the formal right to break ties is allocated in the committee. We assign tie-breaking power randomly in one treatment and based on performance in an unrelated real-effort task (cf. Erkal et al., 2011) in another. In the performance treatment, the chair position is 'earned' and thus comes with a natural notion of legitimacy. Legitimacy is a vital element of how people react to formal power and is relevant in many real-world committees (e.g. Blinder and Morgan, 2005, 2008; Silverman et al., 2014; Karakostas and Zizzo, 2016). Compliance of regular members, in the sense of choosing the chair's preferred 
alternative, with the legitimate chair is predicted by inhibition-related behavior of regular members (Keltner et al., 2003; Anderson and Berdahl, 2002; Lammers et al., 2008).

There are, however, also other possible explanations. Given that the chair worked harder than regular members to obtain her position in the performance treatment, regular members may believe that the chair is entitled to her preferred choice, consistent with arguments brought forward in equity theory (Adams, 1965). Outcome-based economic theories of social or distributional preferences, such as inequity aversion (Fehr and Schmidt, 1999), are, however, ruled out by design as possible explanations of observed behavior. ${ }^{11}$ Finally, legitimacy as one of the key sources of legitimate and referent power (French and Raven, 1968) can also explain an alleviated inclination to side with the chair in the performance treatment. Assuming that performance in the real-effort task 'legitimizes' the chair holding the formal right to break ties, our hypothesis can be stated as follows.

Hypothesis 2 (Legitimacy of chair). Regular members are swayed into voting more often for the chair's preferred alternative $A$ in the performance treatment than in the random treatment in Experiment 1.

Note that the legitimacy treatment is expected to have a higher impact on the behavior of player 2 than on that of player 3 due to the underlying preference structure in the committee. Choosing the chair's preferred alternative $A$ is not only more costly for player 3 ( $A$ is her least-preferred alternative) than for player 2 ( $A$ is her second most-preferred alternative); for player 3 , alternative $A$ is also a weakly dominated strategy and empirical research on voting behavior has consistently shown that those strategies are rarely played by voters for good reason (see details in Section 2.2). Note that the allocation mechanism takes places only once, and before the start of the first voting game. We thus do not expect the impact of the performance-based allocation to be equally strong over all periods because the preference

\footnotetext{
11 Note that, in our experiments, we implement a constant-sum, three-player, one-shot committee game. Every possible outcome induces the same distribution of (in)equity in the committee and, thus, results cannot be explained by prominent theories of social or distributional preferences (cf. Fehr and Schmidt, 1999; Bolton and Ockenfels, 2000) without auxiliary assumptions. The motive of direct reciprocity is also ruled out because each experimental subject interacts with the same member exactly once (see Section 3.1).
} 
structure in the committee is common knowledge and participants receive feedback about the election outcome, which creates learning opportunities through experience. On top of the wellknown fact in the experimental literature that participants learn over time to act in their best interest in strategic environments, committee members have a particularly strong monetary incentive to do so in light of the conflicting preferences in the committee. Legitimacy is a soft manipulation in the sense that it has no direct material consequences in our setting.

In Experiment 2, we investigate whether the labeling of the chair position has a causal effect on behavior in the committee in addition to the asymmetric decision right of the chair to break ties. In the chair-label treatment, the player holding tie-breaking power is referred to as the 'chair', whereas she is referred to as another regular 'member' in the neutral-label treatment. Assuming that the labeling of the chair position increases the salience (e.g. Mehta et al., 1994; Crawford et al., 2008) of the chair and her tie-breaking power, the intuition regarding the behavioral effect is that regular members are more likely to 'give in' and side with the chair if her position is more salient. The behavioral hypothesis can be summarized as follows.

Hypothesis 3 (Labeling of chair role). Regular members are swayed into voting more often for the chair's preferred alternative $A$ in the chair-label treatment than in the neutral-label treatment in Experiment 2.

Behavior across treatments hence directly captures the effect the label of the chair position has on behavior in the committee. The largest change in behavior is expected to come from the regular member in the role of player 2 , for the same reason that was pointed out in Hypothesis 2.

\section{Experiment 1}

In Experiment 1, we investigated the influence of asymmetric tie-breaking power on decisionmaking in committees and quantify the causal effect that tie-breaking power has on behavior when the chair holds formal tie-breaking power legitimately. 


\subsection{Design}

The experiment consisted of two parts. Participants engaged in a real-effort task and then made decisions in committees by voting. Upon arrival, they were randomly allocated to isolated working stations. Printed instructions (see Appendix A) explained all procedures and parts of the experiment. The experiment started after all control questions were answered correctly. The course of the experiment is summarized below. Real-effort task. We employed the word encoding paradigm of Erkal et al. (2011). Participants were presented with words on-screen (e.g., fast, hyper,...) and asked to replace letters with numbers from a cipher table for 7 minutes. The encoding table bijectively maps the alphabet's letters into the numbers 1 to 26 (in random order). The ex-ante probability of becoming chair increased with performance, defined as the number of correctly encoded words. The tournament design elicited participants' willingness to become the committee's chair without introducing carry-over income effects. Conditioning the assignment of the chair role on performance or chance also allowed us to introduce legitimate tie-breaking power as a treatment variable. After the task, participants indicated their willingness to become the committee's chair, referred to as WTP1, on a 10-point Likert scale. We introduced this unincentivized question to augment the real-effort task as the task itself did not control for participants' opportunity cost of exerting effort. Finally, we asked participants about the likelihood that an election would result in a tie to elicit their belief about the decisiveness of the decision right to break ties. As with our WTP1 question, belief elicitation was not incentivized. ${ }^{12}$

Treatments. Using a between-subject design, we varied the allocation mechanism for the chair role. In the random treatment, participants were randomly distributed to player roles. In the performance treatment, the chair role was assigned according to performance in the real effort task. Specifically, the top $1 / 3$ performers within this treatment group were assigned the chair role whereas the remaining player roles were distributed randomly. The

\footnotetext{
12 Belief elicitation was not incentivized as doing so would have increased complexity, weakened monetary incentives in the game, and created hedging possibilities between experimental parts (Blanco et al., 2010). For more details on this issue see Section 5 .
} 
Table 2: Summary of treatments.

\begin{tabular}{lccc}
\hline & \multicolumn{3}{c}{ Chair } \\
\cline { 2 - 4 } & assignment & tournament & label \\
\hline \multirow{2}{*}{ Experiment 1 } & performance & yes & yes \\
& random & yes & yes \\
\hline \multirow{2}{*}{ Experiment 2 } & random & no & yes \\
& random & no & no \\
\hline
\end{tabular}

ex-ante probability of being allocated to either treatment was identical for each participant in a session. Half of the participants in each session were assigned to the random treatment whereas the remaining half was assigned to the performance treatment. Hence, in each session there were two matching groups in which interaction through committee voting took place (i.e., no interaction across matching groups). The two possible treatments, their corresponding procedures, and the random assignment into treatments were made common knowledge in the instructions phase of the experiment. Crucial to our design, the actual information regarding to which treatment participants belonged was only disclosed after the effort task, as well as after the WTP1 and belief questions (see Dal Bó et al., 2010, for a similar design). Incentives in the effort task and the meaning of the WTP1 and belief questions were hence identical between the two treatments. After revealing the treatment information, participants received feedback about their own performance in the effort task and were assigned their player roles, which remained fixed throughout the experiment. This design allowed us to control for the level of effort exerted and thus ensured full comparability of behavior between treatments. Although the chair allocation involved an element of competition, the instructions reminded participants to engage in the effort task only if they wished to become chair, as this was the only incentive for the task. Table 2 provides a summary of the treatments.

Committee game. Participants played the voting game described in Section 2.2 for 4 periods under perfect-stranger matching, i.e., the same participants interacted with each other exactly once. Alternatives were labeled neutrally $(A, B$, or $C)$ and shuffled at the matching 
group level to minimize labeling effects. The three committee members voted simultaneously and independently. The winning alternative was determined according to plurality voting and, in the case of a tie, by the chair's regular vote. Preferences over alternatives in the elections were induced by monetary incentives. We used four different sets of payments that induced strict preferences over the set of alternatives depicted in Table 1. Underlying payoff schedules shared the same ordinal payoff structure: $(17 \succ 12 \succ 7),(16 \succ 11 \succ 6)$, $(14 \succ 9 \succ 4)$, and $(13 \succ 8 \succ 3)$, where numbers denote the payoff in Euros a player received in case her most-preferred, second most-preferred, or least-preferred alternative won the election. Each payoff schedule was used in exactly one period and the order of the presentation was randomized. At the end of each period, participants received feedback about the election outcome. Participants were also informed that only one randomly selected election was used for actual payment. All these measures were taken to rule out confounding carry-over effects from one period to another (e.g., reciprocity or coalition formation).

Procedural details. The experiment was conducted at the experimental economics laboratory (Lakelab) of the University of Konstanz. We recruited 96 participants (48 females, average age 23) from a student pool using the online recruitment system ORSEE. All parts of the experiment were run with the software z-Tree (Fischbacher, 2007). Each of the 4 sessions we ran comprised 24 subjects distributed across two independent matching groups, one per treatment. We thus collected data on 4 independent matching groups per treatment in total. Each session lasted approximately 70 minutes, including payment. The average earnings from the game were about $€ 12$. Participants were paid a show-up fee of $€ 2$ on top of their earnings from one randomly selected election at the end of the experiment.

\subsection{Results}

We start presenting outcomes and behavior in the committee for the case in which one member, the chair, holds the decision right to break ties. Results shed light on whether the chair's formal power was advantageous for the chair or whether it did not bear favorable consequences, as predicted theoretically (see also Hypothesis 1). Recall that alternatives $A$, 
$B$, and $C$ represent the most preferred alternative for the chair, player 3 , and player 2 , respectively, and that we measured the real power of a player by the relative frequency with which committees implemented her most-preferred outcome. The left-hand part in Figure 1(a) shows the relative frequency of committee decisions won by each of the three alternatives (pooled over treatments). Alternative $A$ was the most frequently implemented outcome and in grand total won $56 \%$ of all elections, whereas $C$ won $40 \%$. The election results were clearly inconsistent with the prediction stated in Hypothesis 1, under which we would expect committees to implement $A$ at a rate of $0 \%$. Notably, only $37 \%$ of all observed elections were consistent with the exact behavioral pattern predicted by the game-theoretical model (chair voting for $A$, player 2 and 3 for $C$ ). The formal tie-breaking decision right, contrary to rational-choice expectations, translated into real power for the chair making her at least as powerful as regular members. These observations were corroborated by two-tailed, exact Wilcoxon-signed-rank (WSR) tests run at the level of independent matching groups. We rejected the null hypothesis that the frequency of $A$ being chosen is $33 \%$, both utilizing data from all periods $(N=8, p<0.008)$ and restricting our sample to the last period only $(N=8$, $p<0.016) .{ }^{13}$ The null hypothesis essentially compared the chair's power to the average power of regular committee members. ${ }^{14}$

Next, we isolate a number of important factors that underlie the real power of the chair. To do so, we decompose the chair's real power into direct effects whenever the chair exercised

\footnotetext{
13 Observe that the random treatment steers free of any manipulations of perceived formal power as tiebreaking power was randomly assigned. Restricting our sample to the random treatment only, the chair's real power equals $52 \%$. Notably, all four independent matching groups implemented alternative $A$ at rates higher than $33 \%$. Note also that we did not conduct a two-sided WSR test on this data because the test requires at least five independent observations to detect significance.

14 Of note, we could have adopted the game-theoretical prediction of $0 \%$ implementations of $A$ under the null instead. Obviously, the reported significance of the WSR tests in the main text would have also obtained under this alternative specification. However, $0 \%$ constitutes a boundary point of the outcome space and hypothesis tests on boundary points are associated with many issues. We, therefore, decided on a more conservative approach to establish the real power of the chair. Why 33\%? Observe that regular members in the experiment entered a 50/50 lottery for the committee roles of player 2 and player 3 . The correct ex-ante counterfactual from the chair's perspective was to compare her power to the average power of player 2 and player 3 combined. Given that our measure of power was represented by relative frequencies (adding up to one), we immediately obtained an effective power threshold of $33 \%$ for the chair.
} 


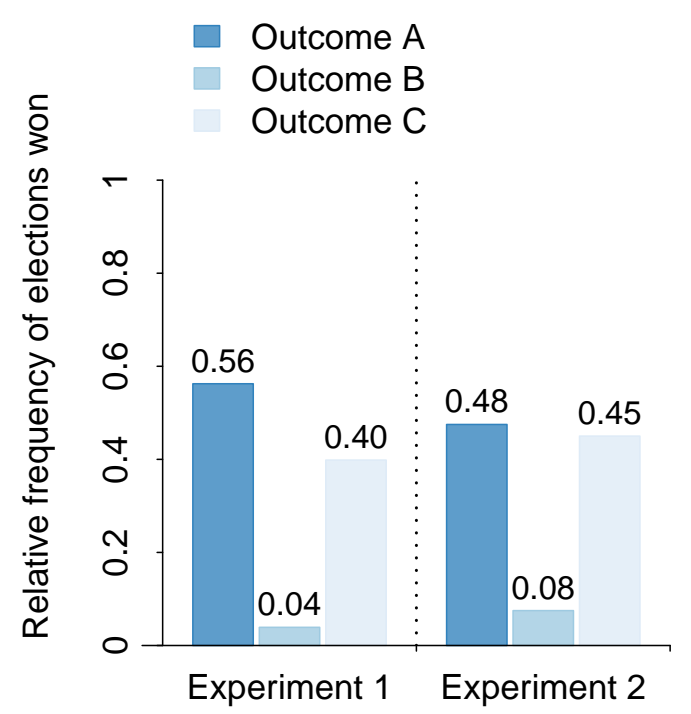

(a) Committee outcomes

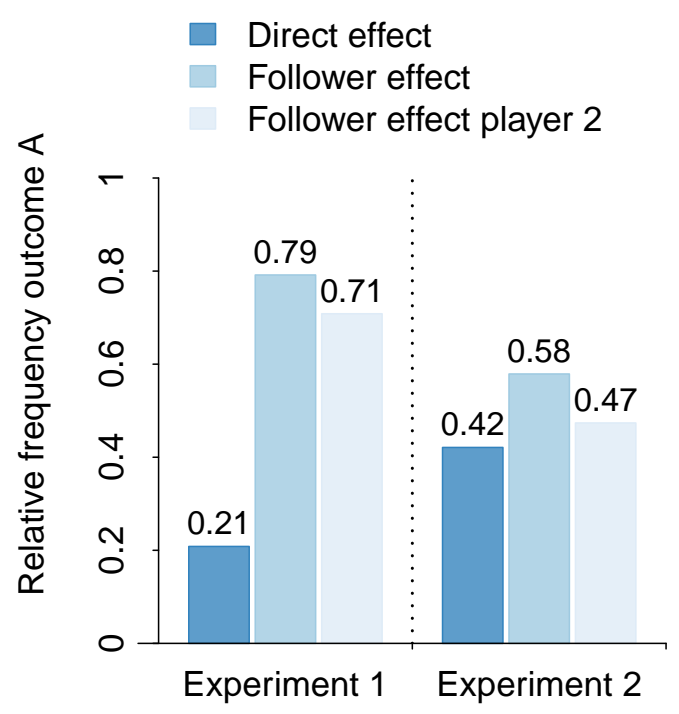

(b) Determinants of real power

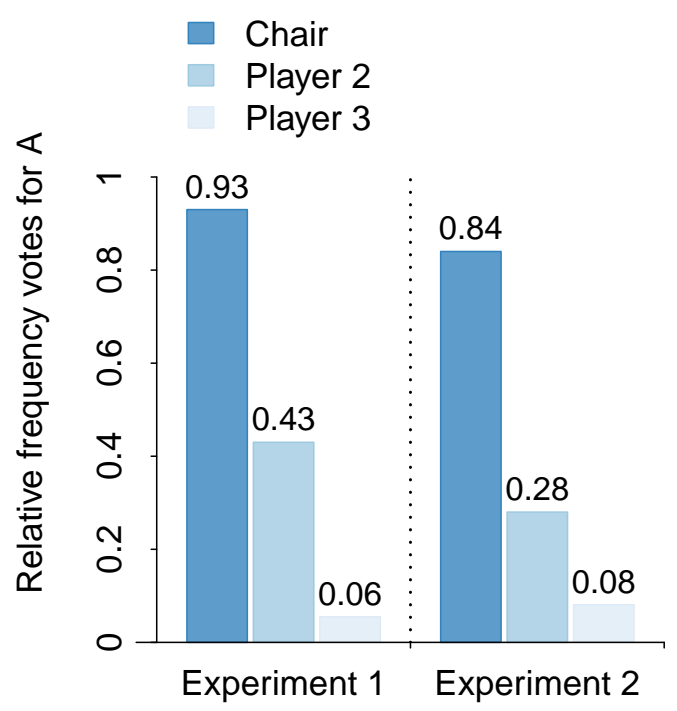

(c) Individual voting behavior

Figure 1: Committee outcomes, determinants of real power, and individual voting behavior over all periods. 
her tie-breaking decision right in favor of $A$ and into follower effects whenever $A$ won the election and at least one regular member voted for $A$. From the left-hand part in Figure (b) it is evident that follower effects were empirically more prominent than direct effects in Experiment 1 . Only $21 \%$ of $A$-outcomes occurred as a consequence of exercising tie-breaking power, whereas $79 \%$ of $A$-outcomes were due to follower effects. A total of $71 \%$ of all $A$ outcomes entailed player 2 voting for $A$; of these, all outcomes were associated with voting profiles that saw the chair vote for alternative $A$ and player 3 vote for either $C(57 \%)$ or $B(14 \%)$. Two two-sided exact WSR tests run at the level of independent matching groups corroborated that follower effects occurred more frequently than direct effects (all periods: $p<0.023$, last period: $p<0.054, N=8$ in each test).

Assessing behavior at the individual level, the left-hand part of Figure 1(c) presents the individual vote frequencies in favor of alternative $A$. We observed stark differences across member roles, which reflected closely the material incentives induced by the committee's preference structure over alternatives. The chair displayed a strong motive to support her favorite option and voted for $A$ in $93 \%$ of all elections. On the contrary, player 3 supported $A$, her least-preferred option, in only $6 \%$ of the elections. Committee decisions in favor of $A$ imposed the highest costs in terms of foregone payoffs for this committee member. Player 2 showed an intermediate level of voting for $A$, which captured her trade-off between the - possibly psychological - motives to follow the chair and the pursuit of her material selfinterest. ${ }^{15}$

To lend further credence to our interpretation that player 2 was willing to forgo significant material benefits as a consequence of following the chair, we calculated her expected payoff of voting for $A$ against the empirically observed behavior of the other committee members. Specifically, we assumed that player 2 adopts a probabilistic voting strategy. With probability $p$, she votes for $A$, with probability $1-p$ she votes for $C$. If $p=1$, she votes for $A$ for sure,

\footnotetext{
15 Table A.1 in the Appendix shows the evolution of the main dependent variables and demonstrates the robustness of our findings across periods. Table A.2 and Table A.3 present a more detailed summary of committee outcomes and individual vote frequencies.
} 
Table 3: Expected payoff in Euros for player 2 voting for $A$ vs voting for $C$.

\begin{tabular}{cccccc}
\hline & \multicolumn{2}{c}{ Experiment 1} & & \multicolumn{2}{c}{ Experiment 2} \\
\cline { 2 - 3 } \cline { 5 - 6 } Prob. vote for $A$ & Performance & Random & & Chair label & No label \\
\hline $100 \%$ & 9.72 & 9.64 & & 9.60 & 9.30 \\
$75 \%$ & 10.67 & 10.67 & & 10.44 & 10.20 \\
$50 \%$ & 11.63 & 11.70 & & 11.28 & 11.11 \\
$25 \%$ & 12.58 & 12.72 & & 12.12 & 12.01 \\
$0 \%$ & 13.53 & 13.75 & & 12.96 & 12.91 \\
\hline
\end{tabular}

Notes: Table reports expected payoffs in Euros for player 2. Payoffs are calculated against the empirically observed behavior of player 3 and chair participants. We set the probability to vote for $B$ at $0 \%$ and consider various levels of probabilities to vote for $A$.

if $p=0$ she does so for $C$. We conveniently set the probability to vote for $B$ to zero, as voting for $B$ was empirically and theoretically irrelevant. Table 3 shows the expected payoffs in Euro amounts of the probabilistic voting strategy at various levels of $p$. Across both treatments expected payoffs were the lowest if player 2 followed the chair and voted for $A$ with certainty. The corresponding figures were $€ 9.72$ in the performance treatment and $€ 9.64$ in the random treatment. A decrease in the probability of voting for $A$, conversely an increase in the probability of voting for $C$, was associated with a monotonic increase in expected payoffs with a peak at $p=0$, i.e., voting for $C$ for sure. Player 2 would have maximized expected payoffs by going against the chair and voting for $C$. Voting for $A$ in comparison to voting for $C$ was associated with an average cost of $€ 3.81$ in the performance treatment and $€ 4.11$ in the random treatment for player $2 .{ }^{16}$

\footnotetext{
${ }^{16}$ Unreported ordinary-least-squares regressions with robust standard errors statistically confirm the differences in expected payoffs between voting for $A$ and voting for $C$. As the dependent variable, we calculated the participant-averaged payoff from the four elections in the experiment for player 2. As independent variables, we included a variable that counts from 0 to 4 how often a player 2 voted for $A$, a treatment dummy, and the interaction term between the count variable and the treatment dummy. Increasing the count by one of voting for $A$ was associated with a decrease in average payoffs by $€ 1.08$ (significant at the $1 \%$ level). We found
} 
Taken together, individual-level behavior demonstrated that follower effects associated with player 2's behavior were one of the sources of the chair's real power. We thus examined player 2's behavior in light of potential treatment differences to further elucidate the driving forces behind the follower effect. Recall that our hypothesis was that performance-based allocation of the tie-breaking decision right would legitimize power, which in turn would sway regular members to vote more often for $A$ in the performance treatment than in the random treatment (see Hypothesis 2). Theory suggested that this argument had little bite for player 3 because alternative $A$ was her least-preferred alternative and so voting for it was associated with high monetary costs. Indeed, data showed player 3 rarely voted for $A$ in any of the treatments and we did not observe any treatment differences in behavior for this member.

To investigate our main treatment hypothesis, which captured the causal effect of holding tie-breaking power legitimately on voting behavior, we ran probit regressions on player 2's propensity to vote for $A$. The dependent variable was the same across models and took the value of 1 if player 2 voted for $A$, and 0 otherwise. Both models in Table 4 confirmed that the performance treatment had a significant effect on the propensity to side with the chair for player 2. The coefficient for the Performance dummy was positive and significant in both models. We also added additional controls to account for treatment-specific learning effects. Whereas the Period variable itself was insignificant, the interaction effect between Performance and Period was significant and negative. This finding pointed towards a decline in the treatment effect on the propensity to side with the chair over time. We therefore computed average marginal effects for the Performance coefficient for each of the four periods in the experiment separately.

In model (2), the treatment effect was positive and significant in the first two periods, but insignificant for later ones. Player 2's probability of voting for $A$ was 36 and 25 percentage points higher in the performance treatment than in the random treatment, in the first two periods of the experiment, respectively. In the last period, we observed no difference no significance for the treatment dummy and no significance for the interaction term. Similar results were obtained, albeit with the opposite sign, by replacing the count to vote for $A$ by a count to vote for $C$. 
Table 4: Probit regressions on player 2's behavior, Experiment 1.

\begin{tabular}{lcc}
\hline DV: vote for A & $(1)$ & $(2)$ \\
\hline Performance & $1.157^{* *}$ & $1.369^{* *}$ \\
& $(0.521)$ & $(0.546)$ \\
Period & -0.083 & -0.090 \\
& $(0.067)$ & $(0.069)$ \\
Performance $\times$ Period & $-0.317^{* *}$ & $-0.340^{* *}$ \\
& $(0.152)$ & $(0.162)$ \\
Words encoded & & $-0.046^{* * *}$ \\
& & $(0.009)$ \\
Decisiveness belief & & 0.008 \\
& & $(0.007)$ \\
WTP1 chair & & 0.147 \\
Constant & & $(0.108)$ \\
& & -0.419 \\
Average marginal effect of performance & & $(0.949)$ \\
at Period 1 & $0.320^{* *}$ & $0.361^{* *}$ \\
at Period 2 & $(0.161)$ & $(0.147)$ \\
Number of participants & 0.206 & $0.250^{*}$ \\
at Period 3 & $(0.153)$ & $(0.141)$ \\
at Period 4 & 0.078 & 0.123 \\
& $(0.157)$ & $(0.147)$ \\
& -0.039 & 0.003 \\
& $(0.165)$ & $(0.155)$ \\
\hline
\end{tabular}

Notes: Probit regressions with standard errors clustered at the matchinggroup level in parentheses. Dependent variable is dummy, 1 if player 2 voted for A. We report average marginal effects of the Performance dummy at different periods separately. Significance codes: ${ }^{* * *}$ at $1 \%$ level, ${ }^{* *}$ at $5 \%$ level, * at $10 \%$ level. 
across treatments. These results pointed towards a short-lived effect of legitimate power on the follower effect within the experiment. A possible explanation for the short-lived character of the treatment effect is given by the feedback and learning opportunities present in our complete-information setting. Another explanation is offered by the possibility of participants forgetting about our one-time legitimacy manipulation, although we reminded participants at the time of each chair-role allocation mechanism before they cast their vote on-screen. Controlling for the number of correctly encoded words in the real-effort task yielded a significant and negative coefficient. Regarding the interpretation of this effect, our conjecture was that performance was largely driven by effort, as intended by the real-effort task (see Erkal et al., 2011). Those who exerted a high level of effort, but were not allocated to the chair role, may have voted against the alternative preferred by the chair out of spite. None of the other variables had a significant impact on player 2's propensity to vote for $A$.

Overall, Experiment 1 demonstrates that the formal decision right to break ties confers real influence over committee decisions for the chair, partly through exercising the decision right to break ties in case of a deadlock, but mainly through follower effects. The treatment comparison provided causal evidence that holding tie-breaking power legitimately swayed player 2 to side with the chair. Observed committee behavior and, in particular, the treatment difference in behavior was consistent with a tendency for compliant or conformist behavior for player 2. Player 2 behavior under legitimized power 'conformed' with behavior and preferences of the chair in the committee to a higher degree than under randomly assigned power. The perception of the attractiveness of the chair's role, elicited before the game, supported these behavioral findings. The majority of participants perceived the chair position as overwhelmingly positive, as evidenced by the high level of effort exerted in the real-effort task (correctly encoded words, mean $M=36.3, S D=7.3$ ) and the high ex-ante stated willingness to become chair (WTP1: $M=8.2, S D=1.7$, on 10-point Likert scale). Participants also overestimated the direct effect of breaking ties: they expected $55 \%$ of all elections to result in a three-way tie, whereas a tie occurred in only $14 \%$.

Our experimental findings bear important implications for committee decisions in the 
presence of a well-defined asymmetry in formal power among committee members. They suggest that the perception of power can lead to strong follower effects even if formal power, the decision right to break ties, does not necessarily lead to influence over outcomes (real power). To gain further insight into the underlying reasons for the observed follower effects in Experiment 1, we conducted a second experiment that assesses, among other things, the perception of chair power before and after the committee elections.

\section{Experiment 2}

Our motivation for the follow-up experiment was two-fold. First, we investigated the general robustness of our Experiment 1. Second, we provided new insights into the perception of formal and real power, as well as into the possible mechanism underlying follower effects. Throughout Experiment 1, we followed the convention of referring to the member holding the tie-breaking decision right as the 'chair' of the committee. The connotations of this particular labeling might have increased the salience of the role and thus possibly contributed to the level-effect of the chair's power. The tournament character in the encoding task in Experiment 1 might have also added to this effect. In Experiment 2, we therefore removed the tournament element by assigning player roles randomly and introduced a control treatment with neutral chair labels (same as a regular member). We also expanded our pre-voting and post-voting questionnaires used in Experiment 1. We elicited WTP-attractiveness measures for all three member roles and tracked how these changed with experience in the committee game. The elicitation allowed us to investigate how experience influenced the participants' perception of power. Further, we included post-voting measures on social status and adaption motives to study potential correlates of follower effects. Except for these changes, the design is identical to that of Experiment 1. 


\subsection{Design}

Treatments and committee game.Participants were allocated randomly to one of two treatments, which differed only in the labeling of the chair role. In the neutral-label treatment, we used 'voter $i$ ' to refer to player roles, with $i \in\{X, Y, Z\}$. In the chair-label treatment, we used the same label as in Experiment 1 ('chair') to refer to the player holding tie-breaking decision right. Table 2 summarizes the treatment differences between experiments. The design allowed us to assess whether or not role labels, independent of the formal decision right, influenced the behavior of the committee members. We employed the same voting game as in Experiment 1.

Furthermore, participants stated the attractiveness of each committee member role before (WTP1) and after (WTP2) the committee voting stage, on 10-point Likert scales. The post-voting questionnaire also included questions on the social status of committee members (taken from de Kwaadsteniet and van Dijk, 2010). In particular, each participant answered two questions about each of the other two committee members' status on 7-point Likert scales: a) "Do you believe you had a higher status than voter j?" and b) "Do you believe you had a lower status than voter j?" The measure of social status $S_{i, j}$ of member $i$ relative to member $j$ was taken as the rating difference between the two questions. If $S_{i, j}>0\left(S_{i, j}<0\right)$, member $i$ attributed a higher (lower) social status to herself than to the other committee member $j$. Participants also answered two questions about about their adaption motives with regard to the behavior of each of the other two members via 7-point Likert scales: a) "To which extent did you feel that you had to adapt your decisions to the decisions of voter $\mathrm{j}$ ?" and b) "To which extent did you feel that voter j had to adapt his or her decisions to your decisions?" The measure of adaption motive $M_{i, j}$ of member $i$ with regard to member $j$ was taken as the rating difference between the two questions. If $M_{i, j}>0\left(M_{i, j}<0\right)$, member $i$ expressed a motive to adapt her behavior to the behavior of member $j$ (an expectation that member $j$ had to adapt her decision to member $i$ 's decision). As in Experiment 1, WTP, social status, and adaption motive questions were not incentivized. 
Procedural details. The experiment was conducted at the Vienna Center for Experimental Economics (VCEE) of the University of Vienna. In total, 120 participants (60 females, average age 25) were recruited from a student pool using the online recruitment system ORSEE. All parts of the experiment were run with the software z-Tree. Each of the 5 sessions we ran comprised 24 subjects distributed in two independent matching groups, one per treatment. We thus collected data on 5 independent matching groups per treatment in total. A session lasted 70 min and average total earnings were about $€ 16$.

\subsection{Results}

The right-hand side in Figure 1(a) to Figure 1(c) presents the outcome distribution, the decomposition of the chair's power into direct effects and follower effects, and the relative frequencies of votes cast in favor of $A$ across member types for Experiment 2. Experiment 2 essentially replicates our main findings from Experiment 1. Election outcomes were inconsistent with rational-choice theory as formulated in Hypothesis 1 . Only $37 \%$ of all observed elections corresponded to the exact behavioral pattern predicted by the game-theoretical model (chair voting for $A$, player 2 and 3 for $C$ ). Alternative $A$ was the most frequently implemented committee decision with $48 \%$, implying a substantial real power of the chair. We also observed that the chair's real power was to a large extent driven by follower effects associated with player 2 voting for $A$. Player 2 would have maximized her expected payoffs by voting for $C$, see Table 3. We ran the same set of hypothesis tests in Experiment 2 as we did for Experiment 1 to corroborate our main findings. The two-sided WSR tests found that the chair was more powerful than regular members (all periods: $p<0.004$, last period: $p<0.086, N=10$ in each test) and that follower effects were as prominent as direct effects (all periods: $p>0.388$, last period: $p>0.718, N=10$ in each test). ${ }^{17}$

\footnotetext{
17 Analogous to the random treatment in Experiment 1, the neutral-label treatment in Experiment 2 steers free of any manipulations of perceived formal power as tie-breaking power was randomly assigned and the chair-role neutrally framed. Restricting our sample to the neutral-label treatment only, the chair's real power equals $46 \%$. A two-sided, exact WSR test on this data signifies that the chair's real power was larger than $33 \%(p=0.063, N=5)$.
} 
Table 5: Probit regressions on player 2's behavior, Experiment 2.

\begin{tabular}{|c|c|c|c|}
\hline DV: vote for $\mathrm{A}$ & (1) & $(2)$ & (3) \\
\hline Neutral Label & $\begin{array}{l}-0.188 \\
(0.691)\end{array}$ & $\begin{array}{c}-0.216 \\
(0.739)\end{array}$ & $\begin{array}{l}-0.140 \\
(0.695)\end{array}$ \\
\hline Period & $\begin{array}{c}-0.486^{* *} \\
(0.224)\end{array}$ & $\begin{array}{c}-0.571^{* *} \\
(0.253)\end{array}$ & $\begin{array}{c}-0.569^{* *} \\
(0.243)\end{array}$ \\
\hline Neutral Label $\times$ Period & $\begin{array}{c}0.234 \\
(0.264)\end{array}$ & $\begin{array}{c}0.242 \\
(0.303)\end{array}$ & $\begin{array}{c}0.245 \\
(0.290)\end{array}$ \\
\hline Adaption motive to chair & & $\begin{array}{c}0.205^{* * *} \\
(0.073)\end{array}$ & \\
\hline Status chair & & & $\begin{array}{c}0.173^{* * *} \\
(0.040)\end{array}$ \\
\hline Decisiveness belief & & $\begin{array}{c}-0.009 \\
(0.006)\end{array}$ & $\begin{array}{l}-0.004 \\
(0.005)\end{array}$ \\
\hline WTP1 chair & & $\begin{array}{c}-0.019 \\
(0.062)\end{array}$ & $\begin{array}{l}-0.031 \\
(0.067)\end{array}$ \\
\hline WTP1 player 2 & & $\begin{array}{c}-0.172^{* *} \\
(0.071)\end{array}$ & $\begin{array}{c}-0.175^{* *} \\
(0.070)\end{array}$ \\
\hline WTP1 player 3 & & $\begin{array}{c}0.232^{* * *} \\
(0.056)\end{array}$ & $\begin{array}{c}0.164^{* * *} \\
(0.045)\end{array}$ \\
\hline Constant & $\begin{array}{c}0.347 \\
(0.481)\end{array}$ & $\begin{array}{c}0.920^{* *} \\
(0.382)\end{array}$ & $\begin{array}{c}0.977^{* *} \\
(0.476)\end{array}$ \\
\hline \multicolumn{4}{|l|}{ Average marginal effects } \\
\hline Adaption motive to chair & & $\begin{array}{c}0.051^{* * *} \\
(0.013)\end{array}$ & \\
\hline Status chair & & & $\begin{array}{c}0.042^{* * *} \\
(0.008)\end{array}$ \\
\hline Number of observations & 160 & 160 & 160 \\
\hline Number of participants & 40 & 40 & 40 \\
\hline Number of clusters & 10 & 10 & 10 \\
\hline
\end{tabular}

Notes: Probit regressions with standard errors clustered at the matchinggroup level in parentheses. Dependent variable is dummy, 1 if player 2 voted for A. We report average marginal effects of adaption motive to chair and status chair separately. Significance codes: ${ }^{* * *}$ at $1 \%$ level, ${ }^{* *}$ at $5 \%$ level, * at $10 \%$ level. 
Next, we ran a series of probit regressions to investigate the factors influencing player 2's decision to follow the chair and vote for $A$. In all models presented, the sample was restricted to player 2 participants and the dependent variable took the value 1 if a player 2 voted for $A$. Table 5 presents the corresponding results. We started with the analysis of whether or not the label of the chair position itself contributed to the follower effect. If the salience of the chair label influenced behavior, player 2 would have been expected to vote for the chair's preferred alternative $A$ more often in the chair-label than the neutral-label treatment, as formulated in Hypothesis 3. We found no support for this hypothesis as there was no significant effect of the neutral-label dummy in any of the models. In grand total, player 2 chose $A$ with a frequency of $22 \%$ in the chair-label treatment and with $33 \%$ in the neutral-label treatment. ${ }^{18}$ The propensity to side with the chair was, however, declining over time as evidenced by the negative and significant coefficient of the period variable. Learning opportunities created by our repeated voting design diminished player 2's propensity to vote for $A$ over time. We again found no impact of chair-label on this learning effect; the interaction term between the neutral-label dummy and period variable was insignificant.

Our treatment comparison provided no evidence for the salience of the chair position ('label effect') influencing the behavior of player 2. The subtle manipulation of the chair label had no effect in our competitive setting, nor were the follower effects in our experiment affected by the label attached to the chair position. However, the chair label constitutes just one of many factors that may contribute to follower effects and, thus, the real power of the chair. Because the asymmetry in the formal decision right was inherently embodied in our committee structure, the non-significance of the treatment effects led to the conjecture that the follower effects were mainly driven by the tie-breaking rule itself and not through the simple labeling effects of the chair position.

\footnotetext{
18 Analogous regression analyses (unreported) also did not detect any treatment differences in individual behavior for the chair or for player 3. The chair's frequency of voting for $A$ was $89 \%$ in the chair-label treatment and $80 \%$ in the neutral-label treatment. For player 3, the only reasonable way to influence the outcome of the committee is to choose $C$ in an effort to gang up against the chair. Player 3 chose $C$ with a frequency of $63 \%$ in the chair-label treatment and $64 \%$ in the neutral-label treatment.
} 
To further substantiate this conjecture, we considered important correlates that would capture the relationship between the perception of power and the follower effects that drove the chair's real influence in the committee. To this end, we included further variables in the regression analysis to control for the ex-ante stated attractiveness for each of the three player roles, as well as for the stated decisiveness belief of the tie-breaking rule. The WTP1 coefficients for the player-2 and player-3 roles were significant; the former negative, the latter positive. One interpretation is that those player 2 participants who evaluated their own role as more positive were participants who followed the reasoning process outlined in Section 2.2 and expected committees to implement $C$. Participants who evaluated the player 3 role as relatively positive did not seem to be aware of this effect. The decisiveness belief, which expresses the participant's belief that the tie-breaking rule will decide the outcome (the direct effect), was insignificant.

Each participant also answered questions about the extent to which they felt the need to adapt their decisions to other members and about the perceived status of other members post-voting, both vital elements of the theories upon which our hypotheses were built. We included both measures (adaption motive and status chair) relating to the chair role into our analysis, with higher values indicating a higher need to adapt behavior and a higher status of the chair, respectively. Both measures were highly correlated with player 2's propensity to vote for $A$, the corresponding coefficients being significant and positive. To quantify this relationship, we estimated the average marginal effects of the variables on the probability of voting for $A$, see Table 5. A one-point increase in the adaption motive was associated with a 5.1 percentage point higher probability of voting for $A$. Similarly, a one-point increase in perceived status of the chair was associated with a 4.2 percentage point increase in the probability of voting for $A$. These results provided evidence that participants consciously admitted following the chair (as opposed to making errors). They were also compatible with the view that the formal decision right to break ties influenced follower behavior through the channel of perceived formal power.

Finally, we provide an analysis of how different (outcome) experiences in voting committees 


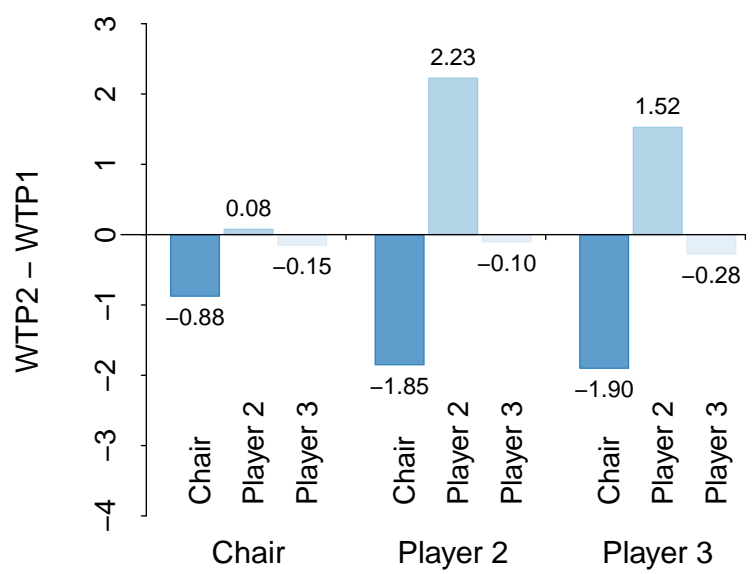

Figure 2: Change in elicited role attractiveness over time.

changed participants' perception of the attractiveness of member roles in the committee, which is crucial for explaining the learning effects of regular members. We start with the observation that, in the pre-voting attractiveness measure of each role (WTP1), participants ascribed the highest attractiveness to the chair role (mean WTP1=8.85), followed by the role of player $2(\mathrm{WTP} 1=5.21)$, and player $3(\mathrm{WTP} 1=4.26)$. At the same time, committees implemented the chair's favorite alternative $A$ with about same frequency as they implemented player 2's favorite alternative $C$, see Figure 1(a), which implies that a player 2 did on average as well as a chair. If the post-voting attractiveness measure (WTP2) was guided by the outcome experience in the committee, we should expect a post-voting decrease in the relative role attractiveness WTP2 between the chair role and the player-2 role.

Figure 2 plots the differences between post-voting and pre-voting attractiveness assessed by all participants $(W T P 2-W T P 1)$, for each member role. The horizontally aligned labels identify participants, while the vertically aligned labels identify the role that was to be assessed. For example, the first bar corresponds to the chair participants' assessments of the chair role, the fourth bar to player 2 participants' assessments of the chair role, and so forth. Figure 2 reveals a heterogeneous pattern in attractiveness adjustments over time and a 
pronounced difference in the role attractiveness elicited from regular members and the chair. Whereas regular member participants adjusted the attractiveness of each member role according to committee voting experience (decrease of chair role, increase of player 2 role), chair participants were, in contrast, much more reluctant to revise the attractiveness of their own role (downwards) and also did not adjust for the relative attractiveness of the player 2 role post-voting (upwards). The failure to recognize the pivotal role of player 2 in the committee established that the heterogeneous pattern of attractiveness adjustments was not driven by potential own-role biases.

To investigate this pattern more thoroughly, we ran a series of OLS regressions on our attractiveness measures. We condensed our attractiveness measures into one dependent variable representing the post-voting attractiveness difference between the chair and player 2 role net of their pre-voting differences: ${ }^{19}$

$$
\left(W T P 2_{\text {Chair }}-W T P 2_{\text {Player } 2}\right)-\left(W T P 1_{\text {Chair }}-W T P 1_{\text {Player } 2}\right) .
$$

Model (1) in Table 6 presents the corresponding regression results. First, note that the dummy for the neutral-label treatment did not have any significant effect in any model specification, i.e., did not influence the individual attractiveness statements. As can be seen, the dummies for the role of player 2 and player 3 were negative and significant. Importantly, a post-estimation hypothesis test did not detect any difference in attractiveness adjustments between regular members $(p=0.586)$. This finding statistically confirmed our previous observation of heterogeneous patterns in attractiveness adjustments between chairs and regular members. Controlling for pre-voting differences, regular members assessed the chair role as less attractive than the player 2 role post-voting.

We also included two variables in the analysis that capture important experiences about the real power of the chair. The first captures the experience of tacit coordination against the

\footnotetext{
19 Notice that the expression can be rewritten as $\left(W T P 2_{C h a i r}-W T P 1_{\text {Chair }}\right)-\left(W T P 2_{\text {Player } 2}-\right.$ $\left.W T P 1_{\text {Player } 2}\right)$ which captures a difference in difference measure of the attractiveness assessments between player roles and over time. The two terms in brackets correspond to the chair and player 2 role attractiveness changes presented in Figure 2.
} 
Table 6: OLS regressions on WTP differences, Experiment 2.

\begin{tabular}{lccc}
\hline DV: & \multicolumn{3}{c}{ WTP difference (chair vs player 2) } \\
\cline { 2 - 4 } & $(1)$ & $(2)$ & $(3)$ \\
\hline Player 2 & $-3.125^{* * *}$ & & \\
& $(1.169)$ & & \\
Player 3 & $-2.475^{* *}$ & & \\
& $(1.081)$ & & -1.126 \\
Neutral Label & -1.175 & -1.276 & $(1.208)$ \\
& $(0.955)$ & $(1.592)$ & $-1.816^{* * *}$ \\
See $(A, C, C)$ & $-1.850^{* * *}$ & -1.944 & $(0.669)$ \\
& $(0.583)$ & $(1.253)$ & $1.040^{*}$ \\
See tie-breaking power & $0.979^{*}$ & 0.843 & $(0.597)$ \\
& $(0.520)$ & $(1.098)$ & -1.495 \\
Constant & 1.437 & 1.755 & $(1.486)$ \\
\hline Number of observations & $(1.428)$ & $(2.855)$ & 80 \\
Robust SE & 120 & 40 & Yes \\
\hline
\end{tabular}

Notes: OLS regressions with robust standard errors in parentheses. Dependent variable in Model (1) to (3): WTP2(Chair) - WTP1(Chair) - (WTP2(Player 2)

- WTP1(Player 2)). Model (2) restricts sample to chair participants only, Model

(3) restricts sample to regular-member participants only. Significance codes: ${ }^{* * *}$ at $1 \%$ level, ${ }^{* *}$ at $5 \%$ level, ${ }^{*}$ at $10 \%$ level.

chair (see variable $(A, C, C)$ ) which counts from 0 to 4 and captures how often a participant saw regular members simultaneously vote for $C$ fixing the chair's vote at $A$. The second captured the experience of the chair breaking at least one tie and counted (again from 0 to 4) how often a participant saw the chair exercising her tie-breaking power. As one would expect, seeing the detrimental consequences of the formal decision right was associated with a significant decrease in the relative attractiveness of the chair role in comparison to the player 2 role, whereas seeing the chair wielding her tie-breaking power was associated with an increase in the same. Models (2) and (3) separate the sample into chair and regular members, respectively. They show that reactions to actual payoff experiences were only significant for 
regular members, but not for chair participants. Holders of the formal decision right did not show a reaction to experience-relevant variables in their attractiveness assessment.

The heterogeneous integration of voting experiences in the committee into post-voting measures of attractiveness is consistent with the growing literature on the non-instrumental value of holding decision rights. According to this literature, decision makers tend to value decision rights per se (Fehr et al., 2013; Bartling et al., 2014) as they are, for instance, motivated to retain control over their own payoffs (Owens et al., 2014) or cherish non-interference by others (Neri and Rommeswinkel, 2016) more generally. Importantly, the finding that chairs attach a more positive value to their own role after experience in the committee, compared to the assessment of regular members, is also related to the well-studied phenomenon of the illusion of control (Langer, 1975; Fast et al., 2009), which has also been evidenced in principals in the context of delegation decisions (e.g. Dominguez-Martinez et al., 2014; Sloof and von Siemens, 2017).

\section{Discussion}

In two independent laboratory experiments, we studied behavior in a committee voting setting in which committee members voted via plurality voting to implement one of three available alternatives. One member, referred to as the chair, held the formal decision right to break ties. Preferences over the alternatives were induced by monetary incentives to represent a situation of conflict: each member strictly preferred to implement a different alternative. Our primary goal was to examine whether the formal decision right to break ties translated into real influence over committee decisions.

Contrary to predictions derived from rational-choice theory, under which non-power holders coordinate against the chair, we observed that the chair's influence over committee decisions was substantial: her most-preferred alternative was implemented frequently. The chair's influence was only partially due to exercising tie-breaking power directly. Our results established that follower effects, in our case the behavior of one particular member deciding to side 
with the chair, were empirically as important as the power to break ties directly. Treatment manipulations and correlates of behavior provide consistent evidence that follower effects are linked to the perception of formal power and associated psychological motives to follow power holders.

Our results are broadly compatible with the inhibition theory of power, which posits that a lack of power is associated with increased inhibition (Keltner et al., 2003). For example, low-power individuals exhibit an elevated tendency to perceive themselves as means to the ends of high-power individuals. Translated into our setting, inhibition-related behavior of regular members could manifest itself in efforts to implement the most-preferred alternative of the power holder by voting for this alternative. Alternately, follower effects can be seen as a consequence of referent power as conceptualized in French and Raven (1968). The basis of referent power is the desire of the powerless to establish or maintain identification with the powerful. Voting for the chair's most preferred alternative can thus be interpreted as a consequence of regular members' desire to identify with the power holder. Whereas our design was not intended to discriminate between competing theories, our results established their potential relevance in a highly competitive setting in which deferring to the powerful is associated with negative material consequences.

In Experiment 1, we increased the size of the follower effect via a treatment manipulation. Legitimate tie-breaking power, i.e., earned through effort provision in an unrelated task, lured regular members into voting for the chair more often than in the case without legitimacy. The treatment effect supports previous findings that have shown that legitimacy is a vital element of how people react to formal power in social contexts (e.g. French and Raven, 1968; Kelman, 1958; Milgram, 1963; Suchman, 1995; Tyler, 2006). In particular, legitimacy is known to moderate the link between power and approach for both powerful and powerless individuals (Lammers et al., 2008). Our results suggest that the moderating effects of legitimacy may also apply to the link between power and inhibition for the powerless.

Prior research has also identified perceived authority or perceived status as vital mechanisms underlying deference to the powerful (Keltner et al., 2003; de Kwaadsteniet and van 
Dijk, 2010; Silverman et al., 2014; Tyler, 2006). Our findings are fully in line with this view. Authority is often conceptualized as stemming from institutionalized roles or arrangements (Weber, 1978b). Status can be derived from a person's own achievement that induces a socially recognized ranking (Ball and Eckel, 1996; Ball et al., 2001). A performance-based allocation of the chair role could have increased the authoritative value of the institutionalized tie-breaking power and, at the same time, could have contributed to a higher social status of the best-performing chair participants. With experience, however, the size of the treatment effect decreased. A possible explanation is given by the feedback opportunities present in the experiments in conjunction with the strong monetary incentive of regular members to coordinate against the chair. It is worth noting that experience did not wash away our baseline effect of real influence, only the treatment difference. One simple way to preserve the positive legitimacy effect for the chair could be to explicitly remind regular members that the chair holds her position for 'good reason'.

Experiment 2 broadly replicated our baseline findings from Experiment 1 in which the chair benefited from the deviations from rational-choice theory systematically. However, we found no evidence that the framing of the chair position itself, our main treatment manipulation in this experiment, influenced behavior. It is well understood in the literature that the powerless are more influenced and constrained by salient information in the environment (Galinsky et al., 2006, 2008). Exploiting this established relationship between salience and power, our hypothesis was that a salient framing of the chair position could increase the influence of psychological motives related to the perception of power to follow the chair. Our null-results are nonetheless compatible with the existing literature on salience and power. The chair label is one of many factors that can potentially influence the perception of power via salient information. Tie-breaking power is inherently embodied in our committee structure, and our baseline effects suggest that this asymmetry alone is sufficient to induce follower effects. Our label manipulation was ineffective in this setting and did not add significantly to the rule-driven effect of tie-breaking power.

Our results add also to existing research on decision making in small groups and moder- 
ating variables that influence decision-making performance. In particular, our results relate to the literature on committee decision making through voting (Hastie and Kameda, 2005; Kameda, 1991; Thompson et al., 1988) and on power asymmetries in small group negotiations (Mannix et al., 1989; Mannix, 1993). In the latter, power is manipulated via the value of the outside options group members receive in case no agreement can be reached in the negotiation. Higher values of outside options constitute credible threats to walk away from the negotiation and therefore imply higher bargaining power, which participants frequently capitalize on. In our setting, however, there is no credible threat the chair could use to influence the decision of others.

\subsection{Limitations and suggestions for future research}

We now address a number of questions regarding the robustness and the limitations of our experimental results, in particular to what extent our results licenses conclusions beyond the population and environment of the laboratory experiment. With regard to the target population, our inference is obviously restricted to our student sample who participated in the experiments. Whereas it might be true that students represent the key decision makers of tomorrow, testing our main findings with real decision makers would further increase confidence in the generalizability of our conclusions.

Regarding the target environment, working with precise game-theoretic predictions allowed us to derive stringent ex-ante hypotheses regarding behavior but confined our analysis to a particular committee environment. Our committee setup represents an abstract simplification of the inner workings of real world committees and neglected several pertinent variables that may also be of importance. We provided participants with complete information about the preference profile in the committee to encourage rational and strategic voting. Based on established findings in the literature (e.g. Granić, 2017; Tyszler and Schram, 2016), it seems reasonable to expect that limiting the information about preferences in the committee may increase the effect of psychological manipulations on individual behavior. We also did not consider communication among committee members, which is a vital element in real-world 
committee decision making and has been studied in small-group negotiations (e.g. Mannix et al., 1989; Mannix, 1993; Thompson et al., 1988). Interestingly, making ex-ante predictions about the direction of the effect of communication and interaction proves difficult. Regular members could communicate to coordinate against the chair or the chair could use the communication channels to influence regular members' behavior. The ambiguity with regard to the effect of communication and interaction indicates a need for further study.

It must also be noted that, although we are among the first to systematically study the impact of small asymmetries induced by formal power, an established stream of literature exists that examines how different voting rules per se influence decision making in committees (Kameda, 1991; Thompson et al., 1988). For example, Hastie and Kameda (2005) study nine different voting rules and how they impact the efficiency of decisions reached in committees. They find plurality and majority-based voting rules to perform best. However, small rule asymmetries such as tie-breaking rules are not investigated. It would be interesting to addend these nine rules with tie-breaking power to study how the original conclusions are affected by the presence of small rule asymmetries.

Furthermore, our experiments were not designed to explicitly discriminate between alternative psychological theories that can explain voting behavior. One of our main findings offers guidance on how future research should proceed in this direction. Tie-breaking power is inherently linked to the committee structure and results have shown that it creates strong motives for regular members to follow power holders. Disentangling tie-breaking power from the follower effects it brings about seems unfeasible. In order to discriminate between alternative theories, future studies need to keep constant the level of formal power and find ways to manipulate its perceived level. For example, it is well understood that the degree of hierarchy in a group can influence the decision making process and, therefore, its decision making performance (Anderson and Brown, 2010; Mannix, 1993). Whereas decision making performance is not the focus of the current study, the tie-breaking power could have implied a perceived hierarchy in the committee. The existing literature has also identified conditions under which steeper hierarchy leads to better performance in group decision making, 
in particular whether hierarchy facilitates or hampers intra-group coordination and whether hierarchy affects group members' motivation. The lessons learned may be transferred into our setting to predict whether hierarchy affects coordination with or against the chair via positive/negative motivation. Our label manipulation in Experiment 2, although ineffective, was a first step in this direction. Due to practical concerns, we did not conduct an experiment that crossed our legitimacy manipulation with the chair-label manipulation. We believe this could be an interesting endeavor. An increase in status via legitimate power could lead to a perceived steeper hierarchical differentiation in the committee. Such a chair label might be hierarchy-enhancing and thereby reinforce the effect of perceived power.

Finally, we incentivize neither our WTP-attractiveness measures nor the elicited decisiveness belief. The existing literature provides several arguments regarding why hypothetical questions might be problematic, which could also explain why some of our non-incentivized measures failed to correlate with observed behavior (Bardsley et al., 2010; Hertwig and Ortmann, 2001). Future research could replace our WTP measures with monetary-based valuations of the chair role that are easy to incentivize, for instance, by either asking participants to state their willingness to pay to become chair using the Becker-DeGroot-Marachak (1964) mechanism or by simply auctioning off the chair role. Belief elicitation could be incentivized via proper scoring rules. We refer the reader to Schlag et al. (2014) for a general discussion of the respective advantages of incentivized and non-incentivized belief elicitation. However, we must note that additional incentives increase the complexity of instructions, weaken monetary incentives in the voting game, and can create hedging possibilities across tasks (Blanco et al., 2010).

\subsection{Practical implications}

Formal decision rights - like the power to break ties - introduce small rule asymmetries in voting-committees that are often treated as innocuous rule addenda due to their limited scope. It is therefore not surprising that we observe a remarkable variety in how the formal decision right to break ties is allocated in real-world committees. It may be based on position, 
experience, or seniority, or emerge implicitly within an organization. In this article, we present evidence that small rule asymmetries should not be allocated based on arbitrary criteria, let alone on criteria that connote legitimacy. Our findings imply that even randomly assigned formal power in a voting board can lead to systematically favoring the power holder under reasonable conditions. Designing committee structures robust to small asymmetries is an important challenge. One possibility for alleviating the distorting effects of small asymmetries could be to assign them randomly or rotate their order among committee members.

\subsection{Conclusion}

This article provided a first step towards an evidence-based understanding of committee decision making in the presence of small rule asymmetries induced by formal decision rights in a setting of conflict. We derived a concise and measurable definition of formal and real power within a stylized committee voting model in which one member, the chair of the committee, holds asymmetric tie-breaking power. Within this framework, we investigated experimentally the causal impact of legitimacy and the salience of the chair position on the chair's effective influence over committee decisions. Two independent laboratory experiments revealed that small asymmetries induced by formal power strongly influenced decision making in ad hoc committees, which stands in contrast to predicted behavior based on rational-choice theory. One of our main results showed that the chair's advantage is explained in large part by regular members siding with the chair against their material self-interests. The observed deviations from rational-choice theory in the legitimacy treatment are compatible with inhibition theory (Keltner et al., 2003; Lammers et al., 2008) and the concept of referent power (French and Raven, 1968). Our analysis highlighted, apart from structural determinants of the strategic environment, that one important source of real power is how regular members perceive the formal tie-breaking right of the chair, or as famously put by Martin (2002): "power resides where men believe it resides". 


\section{References}

Adams, J.S., 1965. Inequity in social-exchange. Advances in Experimental Social Psychology $2,267-299$.

Aghion, P., Tirole, J., 1997. Formal and real authority in organizations. Journal of Political Economy 105, 1-29.

Anderson, C., Berdahl, J.L., 2002. The experience of power: Examining the effects of power on approach and inhibition tendencies. Journal of Personality and Social Psychology 83, $1362-1377$.

Anderson, C., Brion, S., 2014. Perspectives on power in organizations. Annual Review of Organizational Psychology and Organizational Behavior 1, 67-97.

Anderson, C., Brown, C.E., 2010. The functions and dysfunctions of hierarchy. Research in Organizational Behavior 30, 55-89.

Antonakis, J., Bendahan, S., Jacquart, P., Lalive, R., 2010. On making causal claims: A review and recommendations. The Leadership Quarterly 21, 1086-1120.

Arrow, K.J., 1974. The Limits of Organization. W.W. Norton \& Company.

Baker, G., Gibbons, R., Murphy, K.J., 1999. Informal authority in organizations. Journal of Law, Economics, and Organization 15, 56-73.

Ball, S., Eckel, C., Grossman, P.J., Zame, W., 2001. Status in markets. Quarterly Journal of Economics 116, 161-188.

Ball, S.B., Eckel, C.C., 1996. Buying status: Experimental evidence on status in negotiation. Psychology \& Marketing 13, 381-405.

Bardsley, N., Mehta, J., Starmer, C., Sugden, R., 2010. Explaining focal points: Cognitive hierarchy theory versus team reasoning. Economic Journal 120, 40-79.

Bartlett, R., 1989. Economics and Power: An Inquiry into Human Relations and Markets. Cambridge University Press.

Bartling, B., Fehr, E., Herz, H., 2014. The intrinsic value of decision rights. Econometrica 82, 2005-2039.

Becker, G.M., DeGroot, M.H., Marschak, J., 1964. Measuring Utility By a Single Response Sequential Method. Behavioral Science 9, 226-232.

Berry, C.R., Fowler, A., 2015. Cardinals or clerics? congressional committees and the distribution of pork. American Journal of Political Science 60, 692-708.

Berry, C.R., Fowler, A., 2018. Congressional committees, legislative influence, and the hegemony of chairs. Journal of Publich Economics 158, 1-11. 
Blanco, M., Engelmann, D., Koch, A.K., Normann, H.T., 2010. Belief elicitation in experiments: Is there a hedging problem? Experimental Economics 13, 412-438.

Blinder, A.S., 2004. The quiet revolution: central banking goes modern. Yale University Press.

Blinder, A.S., 2007. Monetary policy by committee: Why and how? European Journal of Political Economy 23, 106-123.

Blinder, A.S., Morgan, J., 2005. Are two heads better than one? monetary policy by committee. Journal of Money, Credit, and Banking 37, 798-811.

Blinder, A.S., Morgan, J., 2008. Do monetary policy committees need leaders? a report on an experiment. American Economic Review, Papers \& Proceedings 98, 224-229.

de la Boétie, E., 1975. The Politics of Obedience: the Discourse of Voluntary Servitude. Black Rose Books.

Bolton, G.E., Ockenfels, A., 2000. ERC-a theory of equity, reciprocity, and competition. American Economic Review 10, 166-193.

Camerer, C., 2003. Behavioral Game Theory: Experiments in Strategic Interaction. Princeton University Press.

Cialdini, R.B., Goldstein, N.J., 2004. Social influence: Compliance and conformity. Annual Review of Psychology 55, 591-621.

Crawford, V.P., Gneezy, U., Rottenstreich, Y., 2008. The power of focal points is limited: Even minute payoff asymmetry may yield large coordination failures. American Economic Review 98, 1443-1458.

Dal Bó, P., Foster, A., Putterman, L., 2010. Institutions and behavior: Experimental evidence on the effects of democracy. American Economic Review 100, 2205-2229.

Dhillon, A., Lockwood, B., 2004. When are plurality rule voting games dominance-solvable? Games and Economic Behavior 46, 55-75.

Dominguez-Martinez, S., Sloof, R., von Siemens, F.A., 2014. Monitored by your friends, not your foes: Strategic ignorance and the delegation of real authority. Games and Economic Behavior 85, 289-305.

Erkal, N., Gangadharan, L., Nikiforakis, N., 2011. Relative earnings and giving in a real-effort experiment. American Economic Review 101, 3330-3348.

Farquharson, R., 1969. Theory of Voting. Yale University Press.

Fast, N.J., Gruenfeld, D.H., Sivanathan, N., Galinsky, A.D., 2009. Illusory control: A generative force behind power's far-reaching effects. Psychological Science 20, 502-508. 
Fehr, E., Herz, H., Wilkening, T., 2013. The lure of authority: Motivation and incentive effects of power. American Economic Review 103, 257-272.

Fehr, E., Schmidt, K.M., 1999. A theory of fairness, competition, and cooperation. Quarterly Journal of Economics 114, 817-868.

Fischbacher, U., 2007. z-tree: Zurich toolbox for ready-made economic experiments. Experimental Economics 10, 171-178.

Flynn, F.J., Gruenfeld, D., Molm, L.D., Polzer, J.T., 2011. Social psychological perspectives on power in organizations. Administrative Science Quarterly 56, 495-500.

French, J.R.P., Raven, B.H., 1968. The bases of social power, in: Cartwrigth, D., Zander, A.F. (Eds.), Group Dynamics: Research and Theory. 3 ed.. Harper \& Row, New York, pp. 259-269.

Galinsky, A.D., Gruenfeld, D.H., Magee, J.C., 2003. From power to action. Journal of Personality and Social Psychology 85, 453-466.

Galinsky, A.D., Magee, J.C., Gruenfeld, D.H., Whitson, J.A., Liljenquist, K.A., 2008. Power reduces the press of the situation: Implications for creativity, conformity, and dissonance. Journal of Personality and Social Psychology 95, 1450-1466.

Galinsky, A.D., Magee, J.C., Inesi, M.E., Gruenfeld, D.H., 2006. Power and perspectives not taken. Psychological Science 17, 1068-1074.

Galinsky, A.D., Mussweiler, T., 2001. First offers as anchors: The role of perspective-taking and negotiator focus. Journal of Personality and Social Psychology 81, 657.

Granić, D.G., 2017. The problem of the divided majority: Preference aggregation and uncertainty. Journal of Economic Behavior \& Organization 133, 21-38.

Grossman, S.J., Hart, O.D., 1986. The costs and benefits of ownership: A theory of vertical and lateral integration. Journal of Political Economy 94, 691-719.

Hart, O., Moore, J., 1990. Property rights and the nature of the firm. Journal of Political Economy 98, 1119-1158.

Hastie, R., Kameda, T., 2005. The robust beauty of majority rules in group decisions. Psychological Review 112, 494-508.

Hertwig, R., Ortmann, A., 2001. Experimental practices in economics: A methodological challenge for psychologists? Behavioral and Brain Sciences 24, 433-451.

Kameda, T., 1991. Procedural influence in small-group decision making: Deliberation style and assigned decision rule. Journal of Personality and Social Psychology 61, 245-256.

Karakostas, A., Zizzo, D.J., 2016. Compliance and the power of authority. Journal of Economic Behavior \& Organization 124, 67-80. 
Kelman, H.C., 1958. Compliance, identification, and internalization: Three processes of attitude change. Journal of Conflict Resolution 2, 51-60.

Keltner, D., Gruenfeld, D.H., Anderson, C., 2003. Power, approach, and inhibition. Psychological Review 110, 265-284.

Kohlberg, E., Mertens, J.F., 1986. On the strategic stability of equilibria. Econometrica 54, 1003-1037.

de Kwaadsteniet, E.W., van Dijk, E., 2010. Social status as a cue for tacit coordination. Journal of Experimental Social Psychology 46, 515-524.

Lammers, J., Galinsky, A.D., Gordijn, E.H., Otten, S., 2008. Illegitimacy moderates the effects of power on approach. Psychological Science 19, 558-564.

Langer, E.J., 1975. The illusion of control. Journal of Personality and Social Psychology 32, 311-328.

Magee, J.C., Galinsky, A.D., Gruenfeld, D.H., 2007. Power, propensity to negotiate, and moving first in competitive interactions. Personality and Social Psychology Bulletin 33, 200-212.

Mannix, E.A., 1993. Organizations as resource dilemmas: The effects of power balance on coalition formation in small groups. Organizational Behavior and Human Decision Processes 55, 1-22.

Mannix, E.A., Thompson, L.L., Bazerman, M.H., 1989. Negotiation in small groups. Journal of Applied Psychology 74, 508.

Martin, G.R.R., 2002. A Clash of Kings. Bantam.

Mehta, J., Starmer, C., Sugden, R., 1994. The nature of salience: An experimental investigation of pure coordination games. American Economic Review 84, 658-673.

Milgram, S., 1963. Behavioral study of obedience. Journal of Abnormal and Social Psychology $67,371-378$.

Moulin, H., 1979. Dominance solvable voting schemes. Econometrica 47, 1137-1151.

Neri, C., Rommeswinkel, H., 2016. Decision rights: Freedom, power and interference. Working Paper.

Owens, D., Grossman, Z., Fackler, R., 2014. The control premium: A preference for payoff autonomy. American Economic Journal: Microeconomics 6, 138-161.

Pfeffer, J., 1981. Power in Organizations. Pitman, Marshfield, MA.

Russel, B., 1938. Power: A New Social Analysis. Allen and Unwin. 
Schlag, K., Tremewan, J., van der Weele, J., 2014. A penny for your thoughts: A survey of methods for eliciting beliefs. Experimental Economics 18, 475-490.

Silverman, D., Slemrod, J., Uler, N., 2014. Distinguishing the role of authority "in" and authority "to". Journal of Public Economics 113, 32-42.

Simon, H.A., 1951. A formal theory of the employment relationship. Econometrica 19, 293-305.

Sloof, R., von Siemens, F.A., 2017. Illusion of control and the pursuit of authority. Experimental Economics 20, 556-573.

Sturm, R.E., Antonakis, J., 2015. Interpersonal power: A review, critique, and research agenda. Journal of Management 41, 136-163.

Suchman, M.C., 1995. Managing legitimacy: Strategic and institutional approaches. Academy of Management Review 20, 571-610.

Thompson, L.L., Mannix, E.A., Bazerman, M.H., 1988. Group negotiation: Effects of decision rule, agenda, and aspiration. Journal of Personality and Social Psychology 54, 86-98.

Tyler, R.R., 2006. Why People Obey the Law. Princeton University Press.

Tyszler, M., Schram, A., 2016. Information and strategic voting. Experimental Economics $19,360-381$.

Weber, M., 1978a. Economy and Society: An Outline of Interpretive Sociology. University of California Press.

Weber, M., 1978b. The theory of social and economic organization. New York: Oxford University Press.

Zehnder, C., Herz, H., Bonardi, J.P., 2017. A productive clash of cultures: Injecting economics into leadership research. The Leadership Quarterly 28, 65-85.

Zizzo, D.J., 2010. Experimenter demand effects in economic experiments. Experimental Economics 13, 75-98. 


\section{Appendix}

\section{A Additional tables}

Table A.1: Main dependent variables by period.

\begin{tabular}{|c|c|c|c|c|c|c|c|c|}
\hline & \multicolumn{4}{|c|}{ Experiment 1} & \multicolumn{4}{|c|}{ Experiment 2} \\
\hline & $\mathrm{P} 1$ & $\mathrm{P} 2$ & P3 & $\mathrm{P} 4$ & $\mathrm{P} 1$ & $\mathrm{P} 2$ & P3 & $\mathrm{P} 4$ \\
\hline Outcome $A$ & 0.72 & 0.50 & 0.47 & 0.56 & 0.58 & 0.47 & 0.40 & 0.45 \\
\hline \multicolumn{9}{|l|}{ Follower effects } \\
\hline Total & 0.82 & 0.75 & 0.80 & 0.77 & 0.78 & 0.47 & 0.50 & 0.50 \\
\hline Due to $(A, A, C)$ & 0.60 & 0.50 & 0.67 & 0.55 & 0.43 & 0.28 & 0.33 & 0.18 \\
\hline Due to $(A, A, B)$ & 0.22 & 0.18 & 0.06 & 0.05 & 0.25 & 0.06 & 0.00 & 0.11 \\
\hline \multicolumn{9}{|c|}{ Individual votes for $A$} \\
\hline Chair & 0.94 & 0.97 & 0.84 & 0.97 & 0.90 & 0.95 & 0.80 & 0.90 \\
\hline Player 2 & 0.53 & 0.38 & 0.41 & 0.31 & 0.50 & 0.25 & 0.20 & 0.15 \\
\hline Player 3 & 0.00 & 0.03 & 0.06 & 0.13 & 0.05 & 0.10 & 0.08 & 0.10 \\
\hline
\end{tabular}

Notes: $P 1$ to $P 4$ represent the four periods in the experiments. Outcome $A$ : percentage of elections won by $A$. Follower effects: percentage of outcome $A$ due to follower effects. $(A, A, C)$ : chair voting for $A$, player 2 for $A$, player 3 for $C$. $(A, A, B)$ : chair voting for $A$, player 2 for $A$, player 3 for $B$. Individual votes for $A$ : percentage of voting decisions in favor of $A$. 
Table A.2: Relative frequency of observed strategy profiles over all periods.

\begin{tabular}{lccccccc}
\hline & $(A, C, C)$ & $(A, A, C)$ & $(A, C, B)$ & $(A, A, B)$ & $(A, C, A)$ & $(B, C, C)$ & Other \\
\hline Experiment 1 & & & & & & & \\
Performance & 0.328 & 0.359 & 0.078 & 0.109 & 0.031 & 0.016 & 0.079 \\
Random & 0.406 & 0.281 & 0141 & 0.047 & 0.047 & 0.047 & 0.031 \\
Pooled & 0.367 & 0.320 & 0.109 & 0.078 & 0.039 & 0.031 & 0.056 \\
Experiment 2 & & & & & & & \\
Chair-label & 0.388 & 0.138 & 0.200 & 0.038 & 0.075 & 0.062 & 0.099 \\
Neutral-label & 0.350 & 0.150 & 0.188 & 0.075 & 0.025 & 0.062 & 0.150 \\
Pooled & 0.369 & 0.144 & 0.194 & 0.056 & 0.050 & 0.062 & 0.125 \\
\hline
\end{tabular}

Table A.3: Relative frequency of individual behavior by treatment over all periods.

\begin{tabular}{|c|c|c|c|c|c|c|c|}
\hline & & \multicolumn{3}{|c|}{ Experiment 1} & \multicolumn{3}{|c|}{ Experiment 2} \\
\hline & & Performance & Random & Pooled & Chair-label & Neutral-label & Pooled \\
\hline \multirow{3}{*}{ Chair } & $A$ & 0.938 & 0.922 & 0.930 & 0.888 & 0.800 & 0.844 \\
\hline & $B$ & 0.062 & 0.078 & 0.070 & 0.100 & 0.175 & 0.138 \\
\hline & $C$ & 0.000 & 0.000 & 0.000 & 0.012 & 0.025 & 0.019 \\
\hline \multirow{3}{*}{ Player 2} & $A$ & 0.500 & 0.359 & 0.430 & 0.225 & 0.325 & 0.275 \\
\hline & $B$ & 0.031 & 0.000 & 0.016 & 0.025 & 0.000 & 0.012 \\
\hline & $C$ & 0.469 & 0.641 & 0.555 & 0.750 & 0.675 & 0.712 \\
\hline \multirow{3}{*}{ Player 3} & $A$ & 0.062 & 0.047 & 0.055 & 0.100 & 0.062 & 0.081 \\
\hline & $B$ & 0.219 & 0.188 & 0.203 & 0.275 & 0.300 & 0.288 \\
\hline & $C$ & 0.719 & 0.766 & 0.742 & 0.625 & 0.638 & 0.631 \\
\hline
\end{tabular}




\title{
(FROM HERE: INTENDED FOR ONLINE PUBLICATION)
}

\author{
Supplementary Online Material \\ for \\ "Where Power Resides in Committees" \\ by Granić and Wagner
}

\section{Additional materials: experimental data}

The data used in the analysis for Experiment 1 and Experiment 2 is available here.

\section{Additional materials: instructions}

We provide a complete translation of the written instructions used in Experiment 1 . The instructions for Experiment 2 were identical except for removing any reference of the effort task and player labels, as described in the main text. Figure C.2 to C.4 shows the sample screen-shots of the decision screen that accompanied written instructions. Instructions in the original language (German) are available upon request.

\section{General Instructions}

Welcome! Today's experiment is part of a research project investigating how people make decisions. The expected duration is one hour.

If you have any questions, now or during the course of the experiment, please raise your hand and remain seated. An experimenter will come to you and answer your question.

In addition to the $\mathbf{2}$ Euro which you receive today for showing up on time, you can earn a considerable amount of money. How much money you will earn will depend on your decisions and the decisions of the participants you are going to interact with today. Therefore, it is important that you carefully read the written instructions as well as the instructions on your computer screen before you make decisions.

At the end of the experiment, you will receive the amount of money you have earned today (in addition to the 2 Euro show-up fee) in private and in cash.

You are not allowed to communicate in any form with other participants. Nonobservance of this rule leads to exclusion from the experiment and you will not receive any payment. 
In the experiment, which consists of several parts, you will be asked to make decisions. The experiment will conclude with a questionnaire. Please read the following instructions carefully and then answer the control questions on page 7 .

(End of page 1)

\section{General instructions regarding the experiment}

In the experiment you will participate in a number of elections. Elections takes place in a group of three voters. That is, you and two other participants form one group. The three of you decide on the outcome of the election in your group. In the following, we will call the three voters in one group, Voter 1, Voter 2, and Voter 3.

\section{Casting a ballot}

In each election, you have to cast one vote in favor of one of the three available alternatives (A, B, or C). So do the other two voters in your group. Voting is anonymous and takes place simultaneously. In other words, you don't know the identity of the other two voters, and you also don't know their decisions when casting your vote. After each voter has submitted her/his vote, you will receive feedback about the outcome of the election. The alternative receiving the most votes wins the election.

\section{Payoff profiles of voters}

The three alternatives can differ in terms of their desirability for each of the three voters. The desirability of an alternative is represented by the EURO amount voters receive if the respective alternative wins the election. The payoffs voters receive depend on the outcome of the election, i.e. on which alternative wins the election.

The table in Screenshot 1 below shows an example of a payoff profile of an election group (the Euro amounts in the example are different from the ones used in the actual experiment). For each election in the experiment, the structure of payoffs is the same as in the example in Screenshot 1. The structure of a payoff profile is such that for one voter, alternative A is the most desirable alternative, alternative $\mathrm{B}$ the second most desirable alternative, and $\mathrm{C}$ the least desirable alternative. For another voter, $\mathrm{B}$ is most desirable, $\mathrm{C}$ is second most desirable and $\mathrm{A}$ is least desirable alternative. For the third voter, $\mathrm{C}$ is the most desirable alternative, A the second most desirable alternative, and B is the least desirable alternative.

The payoff profile in the table reads as follows:

- If A wins the election, Voter 1 receives 600 Euro, Voter 2 receives 400 Euro, and Voter 3 receives 200 Euro.

- If $\mathbf{B}$ wins the election, Voter 1 receives 400 Euro, Voter 2 receives 200 Euro, and Voter 3 receives 600 Euro. 
- If $\mathbf{C}$ wins the election, Voter 1 receives 200 Euro, Voter 2 receives 600 Euro, and Voter 3 receives 400 Euro.

\begin{tabular}{|l|c|c|c|}
\hline & If alternative A wins & If alternative B wins & If alternative C wins \\
\hline Voter 1 & $€ 600$ & $€ 400$ & $€ 200$ \\
\hline Voter 2 & $€ 400$ & $€ 200$ & $€ 600$ \\
\hline Voter 3 & $€ 200$ & $€ 600$ & $€ 400$ \\
\hline
\end{tabular}

Screenshot 1: Example payoff profile.

(End of page 2)

Important: Your payoff (in Euro) only depends on which alternative wins the election. In the example above, Voter 1 receives 400 Euro if B wins independently of whether she/he actually voted for B or not.

\section{Voting method}

The alternative which receives the most votes wins the election. In case of a tie among alternatives, the following rule applies: One Voter assumes the role of the "chairman" in the voting group (see description below). The winner of the election in case of a tie is then the alternative the chairman has voted for.

Example: Suppose one voter votes for A, one voter votes for B and one voter votes for C, that is, each alternative receives exactly one vote. Assume that the chairman has voted for alternative $\mathrm{C}$, then alternative $\mathrm{C}$ is the winner of the election.

\section{Course of the experiment}

Now that you know the general rules of the elections in the experiment, let's summarize the course of the experiment:

- Before the start of the first election in the experiment, you will be asked to work on a task that influences the probability of you being the "chairman" in the elections (the task and the exact rules on how the chairman role is determined will be explained on the next page in detail).

- After this task, you will receive information whether you are the "chairman" or not. If you are assigned to the chairman role, you will assume the chairman role in every election.

- Then, you participate in a series of four elections. In each of the four elections, you will meet two other participants (details regarding the elections are provided on page 6).

If you have any questions regarding the instructions or the course of the experiment, please raise your hand and remain seated. An experimenter will come to you and answer your question. 
(End of page 3)

\section{Explanation: How the chairman role is assigned}

Whether you will be chairman in all elections or not depends either:

- on your performance in the encoding task, or

- is determined randomly.

\section{Encoding task}

Before the first election, you will participate in a so-called encoding task. Your performance in this task influences the probability of you becoming "chairman" or not: the more words you encode correctly, in comparison to the other participants, the higher is the likelihood of you being assigned to the chairman role. The encoding task is the same for all participants. Different words are presented to you on screen, one after another. Your task is to replace each letter in the presented word with a number. The encoding table (see Table 1 on page 8) shows for each letter the corresponding number with which each letter has to be replaced in a given word.

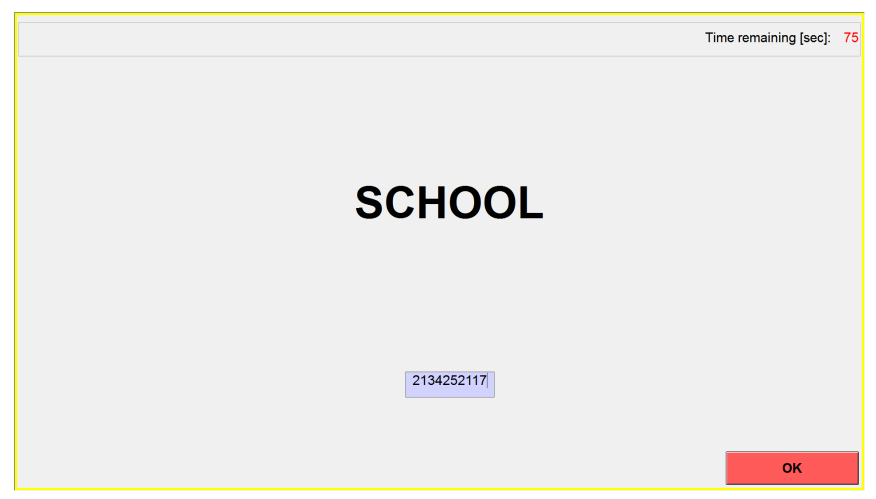

Screenshot 2: Example encoding task.

Example: Screenshot 2 displays the word SCHOOL. From the encoding table (see page 8), you can see that the letters of the word SCHOOL need to be replaced by the following numbers: $\mathrm{S}=13, \mathrm{C}=14, \mathrm{H}=22, \mathrm{O}=21, \mathrm{O}=21, \mathrm{~L}=3$. To correctly encode this word, enter the number 13142221213 into the corresponding text field displayed on screen and then click OK.

When you encoded a word correctly, the next word will be displayed on screen. In total, you have $\mathbf{7}$ minutes for the task. All participants are presented with the same words in the same order. The computer will record how many words you encode correctly in the task. 
(end of page 4)

\section{Random draw}

After the encoding task the computer draws randomly how the role of the chairman is assigned. The role will either be assigned according to performance in the encoding task (with probability $50 \%$ ) or will be assigned randomly (with probability $50 \%$ ):

- If the role of the chairman is assigned according to performance in the encoding task, it means according to the number of words correctly encoded. If your number of correctly encoded words belongs to the top $33 \%$ of all participants in the encoding task you will be assigned the role of the chairman. (In case that two or more top performing participants encoded the same number of words correctly, each top performer has the same chance of becoming the chairman). If your number of words encoded does not belong to the top $33 \%$ of all performances, you will not be assigned the role of the chairman in the experiment.

- If the role of the chairman is assigned randomly, it is assigned independently of the number of words you encoded correctly. A participant is then randomly assigned to the role of the chairman for all elections with a probability of $33 \%$ (because only one voter in a group will be chairman).

After completing the encoding task, every participant will be informed about how many words she/he encoded. Every participant will be informed about whether the chairman role is assigned randomly by the computer or according to performance in the encoding task. Please notice that the outcome of the random draw is the same for every participant you interact with today (i.e. for each participant you interact with today the role will be assigned either by a random draw or according to the performance).

Furthermore, each participant will be privately informed whether she/he is chairman or not. The role of the chairman is assigned before the first election and remains fixed for all elections. In other words, if you are chairman, you are chairman in each election. If you are not the chairman, you will be not be chairman in any of the elections. The table displaying the payoff profile will also indicate which of the three voters in your group takes the chairman role in the election.

Note: The more words you encode in the encoding task within 7 minutes, the higher are your chances of becoming chairman in the elections. That is, if you would like to be chairman, the best you can do is to encode as many words as possible. If you don't want to be chairman, the best you can do is to encode as few words as possible.

(end of page 5) 


\section{Elections and payoffs}

You will participate in a total of four elections. In each election, you will interact with two other participants with which you haven't interacted before. That is, you will never interact with a participant more than once.

At the beginning of each election, you are told whether you are Voter 1, Voter 2, or Voter 3 and informed about who of the three voters assumes the chairman role in your voting group. You will also see this information in the table summarizing the payoff profile of the election. As already mentioned, your task in an election is to vote for one of the three available alternatives, A, B, or C. So do the other two voters in your group. The outcome of the election depends on your decision and the decisions of the other two voters. Therefore, it is important to pay attention to the table displaying the payoff profile of all voters before taking your decision.

Once all voters have made a decision, the number of votes each alternative received will be displayed. The alternative with the most votes wins the election. Only in case of a tie between two or more alternatives, the winner of the election is the alternative the chairman has voted for.

Your payoff from an election only depends on the outcome, i.e. the winning alternative in the election. It is independent of whether you casted a vote for the winning alternative or not. Each voter receives the payoff specified in her/his payoff profile for the winning alternative. Then, another election starts. Please notice that the payoff profile can change with each election. Please recall that the chairman role is assigned before the first election and remains fixed over the course of all four elections.

\section{How your payoff is determined}

After all four elections, the computer will randomly draw one of the four elections. The payoff you received in this randomly drawn election is the Euro amount you will earn (and paid out) in the experiment. This random draw will take place at the end of the experiment, i.e. after you made all your decisions. Of course, the 2 Euro show-up fee will be added to the realized Euro amount from the chosen election.

Are there any questions? If so, please raise your hand and remain seated. An experimenter will come to you and answer your question.

(end of page 6) 


\section{Control questions}

Please answer all control questions. If you have any questions, please raise your hand and remain seated. An experimenter will come to you and answer your question.

Question 1: When and how often will you engage in the encoding task? (please mark the correct answer)

O Before each election.

O Only once before the first election.

Question 2: In which case does the chairman's vote decide the winning alternative in an election? (please mark the correct answer)

O Always.

O Only if there is a tie.

Question 3: If I want to be the chairman, the best I can do is to encode as many words as possible, because during the encoding task I don't know whether the role of the chairman is assigned randomly or by performance in the encoding task (for each participant I interact with). (please mark the correct answer)

O True.

O False.

Question 4: If I am assigned to the role of the chairman I maintain this role for every election today. (please mark the correct answer)

O True.

O False.

Question 5: In each of the four elections, I interact with two other participants I haven't interacted before. (please mark the correct answer)

O True.

O False.

Question 6: The payoff I receive for one election only depends on: (please mark the correct answer)

O The winning alternative of the election. 
O The alternative I voted for in the election.

Question 7: Consider the payoff profile example shown in screenshot 1 (page 2). If you are voter 2 and alternative $\mathrm{B}$ wins the election you receive: (please mark the correct answer)
O 200 Euro.
O 400 Euro.
O 600 Euro.

(end of page 7 )

\section{Encoding table}

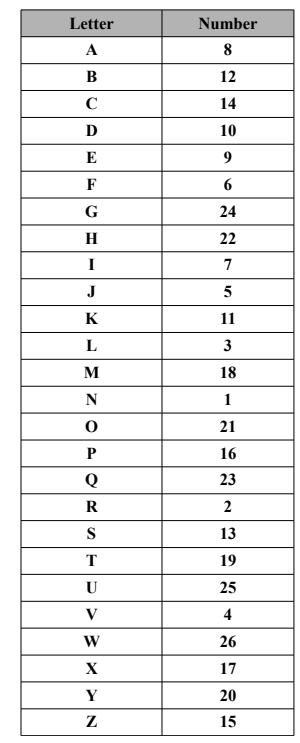

Figure A.1: Encoding table.

(end of page 8 and end of written instructions) 


\section{Additional materials: screenshots}

\section{SCHOOL}

2134252117

Figure C.1: Screenshot real-effort task (Experiment 1).

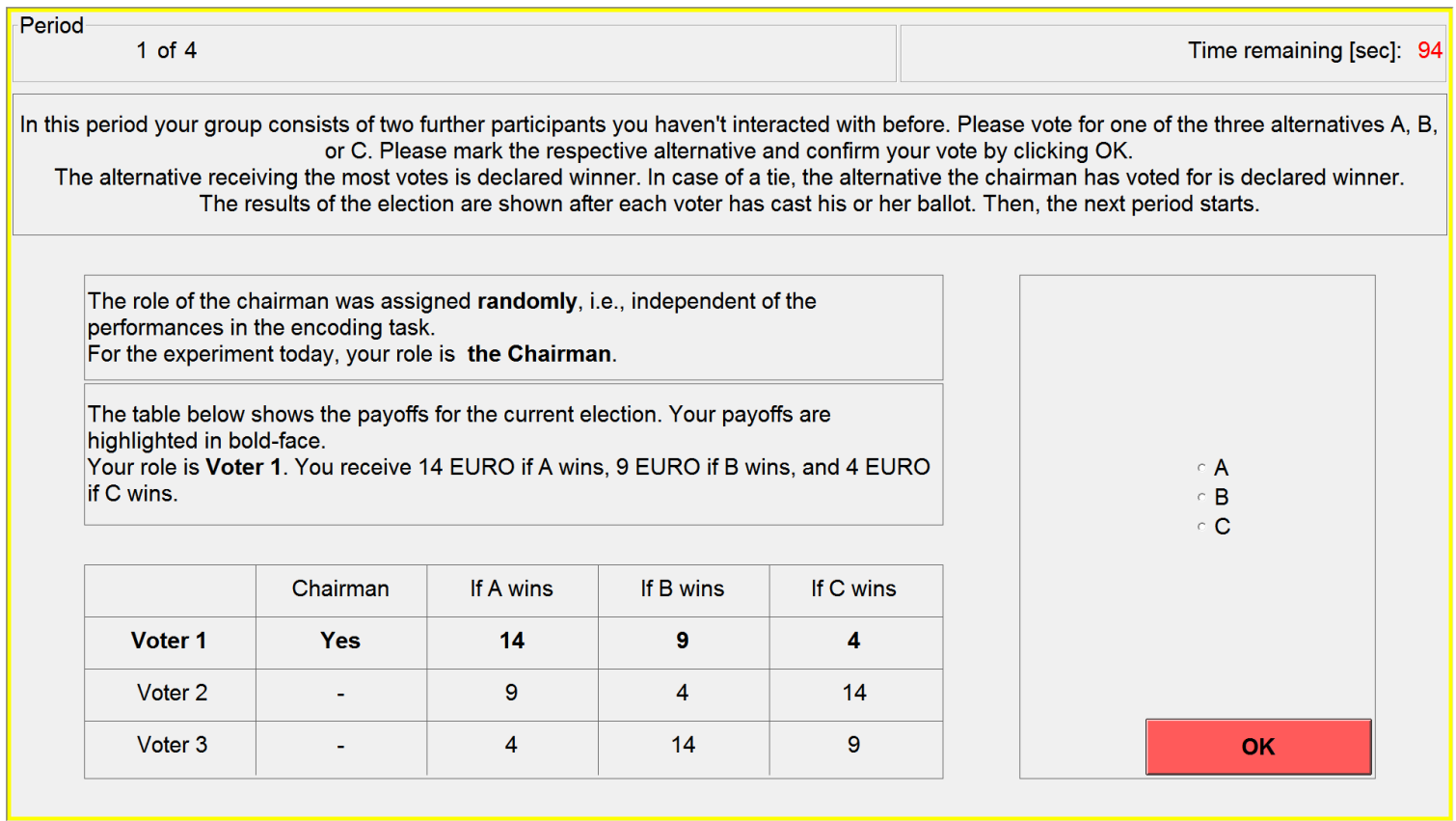

Figure C.2: Screenshot voting stage (Experiment 1). 


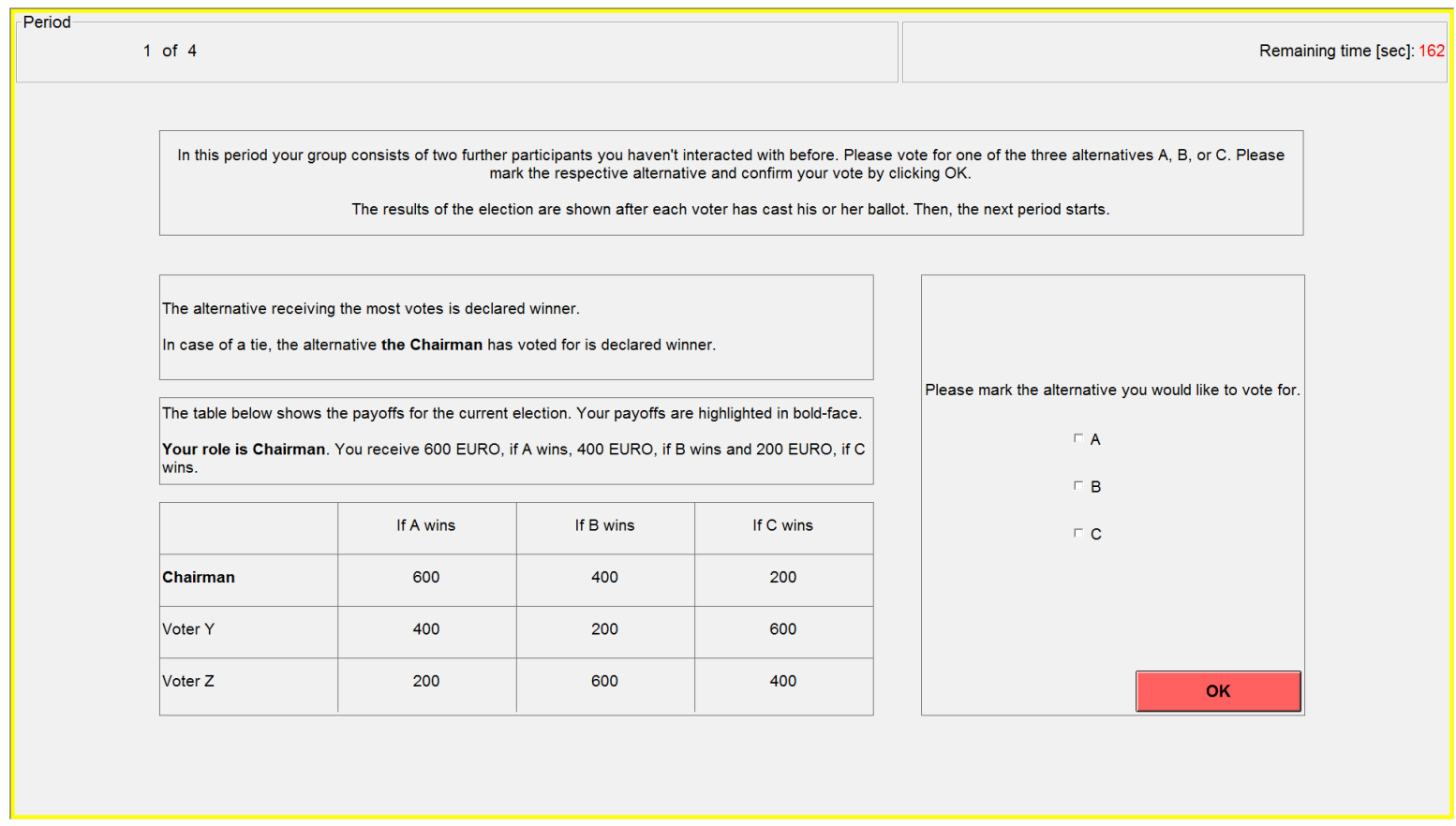

Figure C.3: Screenshot voting stage (chair-label treatment, Experiment 2).

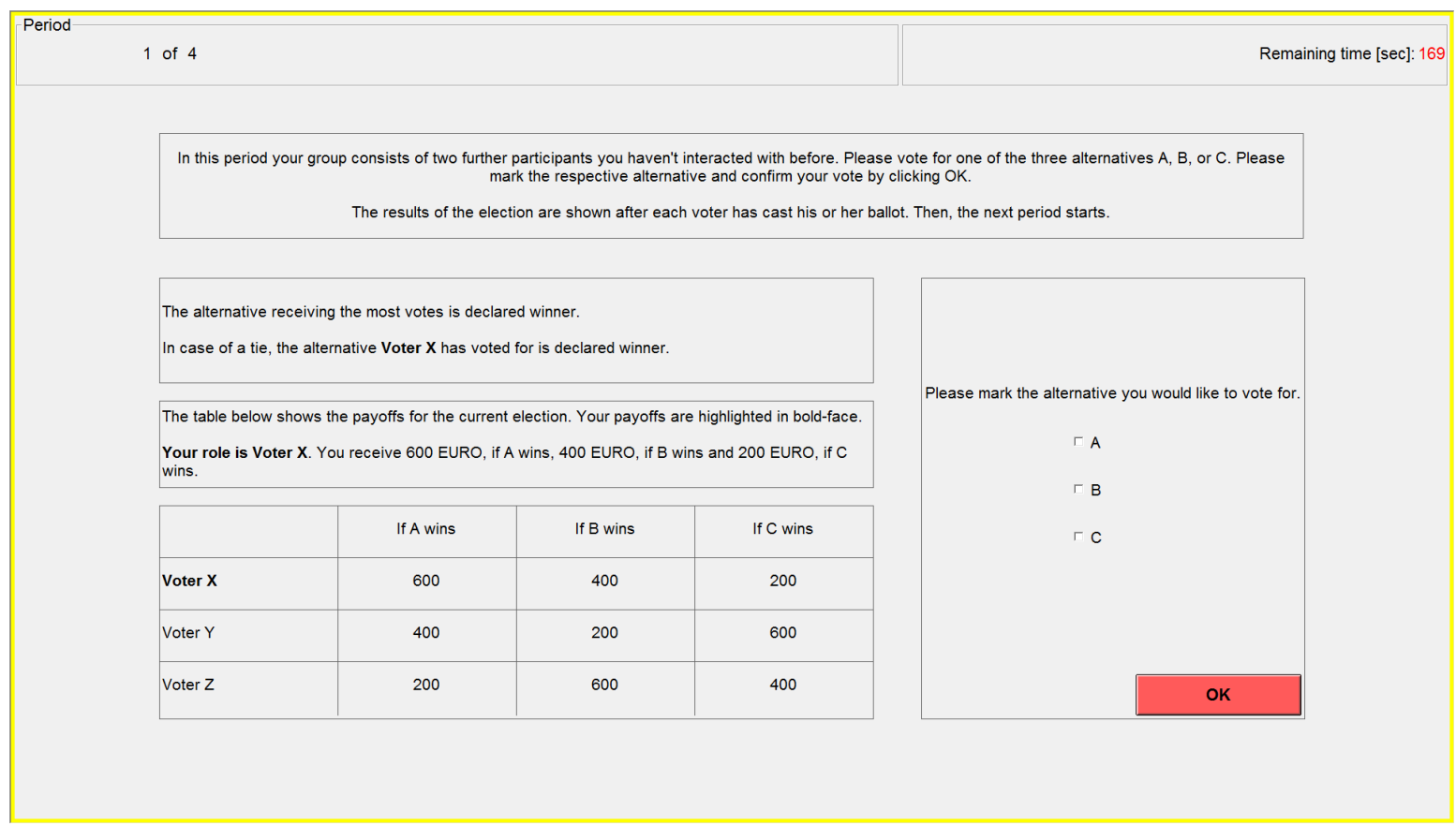

Figure C.4: Screenshot voting stage (neutral-label treatment, Experiment 2). 


\section{Additional materials: data reporting main variables}

Table C.1: Main dependent variables per independent matching group, Experiment 1.

\begin{tabular}{ccccc}
\hline Matching group & Treatment & A Wins & Direct effect & Follower effect \\
\hline 1 & Random & 0.500 & 0.063 & 0.438 \\
2 & Random & 0.563 & 0.063 & 0.500 \\
3 & Random & 0.375 & 0.375 & 0.000 \\
4 & Random & 0.625 & 0.063 & 0.563 \\
5 & Performance & 0.875 & 0.125 & 0.750 \\
6 & Performance & 0.563 & 0.125 & 0.438 \\
7 & Performance & 0.625 & 0.125 & 0.500 \\
8 & Performance & 0.375 & 0.000 & 0.375 \\
\hline
\end{tabular}

Note: 16 distinct elections in each matching group.

Table C.2: Main dependent variables per independent matching group, Experiment 2.

\begin{tabular}{ccccc}
\hline Matching group & Treatment & A Wins & Direct effect & Follower effect \\
\hline 1 & Chair-label & 0.563 & 0.250 & 0.313 \\
2 & Chair-label & 0.313 & 0.125 & 0.188 \\
3 & Chair-label & 0.438 & 0.313 & 0.125 \\
4 & Chair-label & 0.750 & 0.250 & 0.500 \\
5 & Chair-label & 0.375 & 0.125 & 0.250 \\
6 & Neutral-label & 0.438 & 0.125 & 0.313 \\
7 & Neutral-label & 0.563 & 0.125 & 0.438 \\
8 & Neutral-label & 0.375 & 0.313 & 0.063 \\
9 & Neutral-label & 0.563 & 0.063 & 0.500 \\
10 & Neutral-label & 0.375 & 0.313 & 0.063 \\
\hline
\end{tabular}

Note: 16 distinct elections in each matching group. 
Table C.3: Relative frequency of voting for A, Experiment 1.

\begin{tabular}{|c|c|c|c|c|c|c|}
\hline & \multicolumn{4}{|c|}{ Performance treatment } & \multirow{2}{*}{\multicolumn{2}{|c|}{ Player 3}} \\
\hline & $\mathrm{Ch}$ & & Plas & r 2 & & \\
\hline \multirow{4}{*}{ Vote for $\mathrm{A}$} & Mean & $\mathrm{SD}$ & Mean & $\mathrm{SD}$ & Mean & SD \\
\hline & 0.94 & 0.11 & 0.50 & 0.30 & 0.06 & 0.14 \\
\hline & \multicolumn{4}{|c|}{ Random treatment } & & \\
\hline & \multicolumn{2}{|c|}{ Chair } & \multicolumn{2}{|c|}{ Player 2} & \multicolumn{2}{|c|}{ Player 3} \\
\hline & Mean & $\mathrm{SD}$ & Mean & $\mathrm{SD}$ & Mean & SD \\
\hline Vote for A & 0.92 & 0.20 & 0.36 & 0.41 & 0.05 & 0.19 \\
\hline
\end{tabular}

Note: Mean and standard deviation (SD). Number of observations in each cell is 16 .

Table C.4: Relative frequency of voting for A, Experiment 2.

\begin{tabular}{|c|c|c|c|c|c|c|}
\hline & \multicolumn{4}{|c|}{ Chair-label treatment } & \multirow{2}{*}{\multicolumn{2}{|c|}{ Player 3}} \\
\hline & $\mathrm{Ch}$ & & Play & 2 & & \\
\hline \multirow{4}{*}{ Vote for $\mathrm{A}$} & Mean & $\mathrm{SD}$ & Mean & $\mathrm{SD}$ & Mean & $\mathrm{SD}$ \\
\hline & 0.89 & 0.22 & 0.22 & 0.23 & 0.10 & 0.25 \\
\hline & \multicolumn{4}{|c|}{ Neutral-label treatment } & \multirow{2}{*}{\multicolumn{2}{|c|}{ Player 3}} \\
\hline & \multicolumn{2}{|c|}{ Chair } & \multicolumn{2}{|c|}{ Player 2} & & \\
\hline & Mean & $\mathrm{SD}$ & Mean & $\mathrm{SD}$ & Mean & $\mathrm{SD}$ \\
\hline Vote for $\mathrm{A}$ & 0.80 & 0.25 & 0.32 & 0.33 & 0.06 & 0.16 \\
\hline
\end{tabular}

Note: Mean and standard deviation (SD). Number of observations in each cell is 20 . 
Table C.5: Descriptive statistics perception of power variables, Experiment 1.

\begin{tabular}{|c|c|c|c|c|c|c|}
\hline \multicolumn{7}{|c|}{ Performance treatment } \\
\hline & \multicolumn{2}{|c|}{ Chair } & \multicolumn{2}{|c|}{ Player 2} & \multicolumn{2}{|c|}{ Player 3} \\
\hline & Mean & $\mathrm{SD}$ & Mean & $\mathrm{SD}$ & Mean & $\mathrm{SD}$ \\
\hline Words & 44.69 & 3.05 & 34.44 & 6.68 & 33.94 & 5.73 \\
\hline WTP1 & 9.12 & 1.45 & 8.94 & 1.44 & 8.56 & 1.86 \\
\hline WTP2 & 8.56 & 2.00 & 8.56 & 1.86 & 7.50 & 3.35 \\
\hline \multirow[t]{4}{*}{ Belief } & 61.06 & 20.63 & 49.31 & 20.51 & 55.69 & 21.85 \\
\hline & \multicolumn{4}{|c|}{ Random treatment } & \multirow{2}{*}{\multicolumn{2}{|c|}{ Player 3}} \\
\hline & $\mathrm{Ch}$ & & Pla & er 2 & & \\
\hline & Mean & $\mathrm{SD}$ & Mean & $\mathrm{SD}$ & Mean & SD \\
\hline Words & 34.62 & 6.42 & 33.81 & 7.66 & 36.12 & 7.42 \\
\hline WTP1 & 8.69 & 1.85 & 9.12 & 1.36 & 8.50 & 2.25 \\
\hline WTP2 & 8.75 & 2.14 & 7.31 & 3.20 & 8.31 & 2.41 \\
\hline Belief & 53.38 & 23.19 & 59.62 & 29.09 & 48.75 & 24.89 \\
\hline
\end{tabular}

Note: Mean and standard deviation (SD). Number of observations in each cell is 16 . 
Table C.6: Descriptive statistics perception of power variables, Experiment 2.

\begin{tabular}{lcccccc}
\hline & \multicolumn{5}{c}{ Chair } & \multicolumn{2}{c}{ Player 2 } & \multicolumn{2}{c}{ Player 3 } \\
& Mean & SD & Mean & SD & Mean & SD \\
\hline WTP1 Chair & 8.70 & 1.95 & 8.90 & 2.02 & 8.60 & 1.90 \\
WTP1 Player 2 & 5.00 & 2.70 & 5.60 & 2.14 & 5.00 & 2.36 \\
WTP1 Player 3 & 4.25 & 2.43 & 4.05 & 2.37 & 5.25 & 2.12 \\
WTP2 Chair & 8.10 & 2.47 & 7.15 & 2.78 & 6.95 & 2.58 \\
WTP2 Player 2 & 4.90 & 2.65 & 7.75 & 2.24 & 6.20 & 3.02 \\
WTP2 Player 3 & 3.75 & 2.27 & 4.00 & 2.49 & 5.25 & 2.81 \\
Belief & 58.90 & 26.07 & 44.10 & 20.08 & 42.35 & 19.46 \\
Status Chair & NA & NA & -0.10 & 3.60 & -0.10 & 4.02 \\
Adaption motive to Chair & NA & NA & 0.85 & 2.50 & 1.35 & 2.76 \\
& \multicolumn{5}{c}{ Neutral-label treatment } & \\
& \multicolumn{7}{c}{ Chair } & Player 2 & Player 3 \\
& Mean & SD & Mean & SD & Mean & SD \\
\hline WTP1 Chair & 9.35 & 1.63 & 8.50 & 2.74 & 9.05 & 1.96 \\
WTP1 Player 2 & 5.35 & 2.74 & 5.05 & 1.90 & 5.25 & 2.40 \\
WTP1 Player 3 & 4.00 & 2.47 & 3.90 & 1.89 & 4.10 & 2.59 \\
WTP2 Chair & 8.20 & 2.78 & 6.55 & 3.20 & 6.90 & 3.58 \\
WTP2 Player 2 & 5.60 & 3.05 & 7.35 & 2.76 & 7.10 & 3.14 \\
WTP2 Player 3 & 4.20 & 3.22 & 3.75 & 2.00 & 3.55 & 2.74 \\
Belief & 61.50 & 25.98 & 42.80 & 23.78 & 47.40 & 29.09 \\
Status Chair & NA & NA & -0.05 & 4.02 & -2.20 & 4.15 \\
Adaption motive to Chair & NA & NA & 0.35 & 2.87 & 1.95 & 3.05 \\
\hline
\end{tabular}

Note: Mean and standard deviation (SD). Number of observations in each cell is 20. 
Table C.7: Correlation matrix perception of power variables, Experiment 1.

\begin{tabular}{|c|c|c|c|c|c|c|c|c|}
\hline & \multicolumn{4}{|c|}{$\begin{array}{c}\text { Performance treatment } \\
\text { Chair }\end{array}$} & \multicolumn{4}{|c|}{$\begin{array}{c}\text { Random treatment } \\
\text { Chair }\end{array}$} \\
\hline & Words & WTP1 & WTP2 & Belief & Words & WTP1 & WTP2 & Belief \\
\hline \multirow[t]{2}{*}{ Words } & 1.00 & 0.31 & -0.42 & -0.09 & 1.00 & 0.23 & 0.17 & 0.35 \\
\hline & & 0.243 & 0.107 & 0.753 & & 0.402 & 0.524 & 0.185 \\
\hline \multirow[t]{2}{*}{ WTP1 } & 0.31 & 1.00 & 0.23 & -0.24 & 0.23 & 1.00 & 0.90 & 0.20 \\
\hline & 0.243 & & 0.399 & 0.361 & 0.402 & & 0.000 & 0.461 \\
\hline \multirow[t]{2}{*}{ WTP2 } & -0.42 & 0.23 & 1.00 & -0.14 & 0.17 & 0.90 & 1.00 & 0.17 \\
\hline & 0.107 & 0.399 & & 0.609 & 0.524 & $<0.001$ & & 0.537 \\
\hline \multirow[t]{4}{*}{ Belief } & -0.09 & -0.24 & -0.14 & 1.00 & 0.35 & 0.20 & 0.17 & 1.00 \\
\hline & 0.753 & 0.361 & 0.609 & & 0.185 & 0.461 & 0.537 & \\
\hline & & Play & ar 2 & & & Pla & & \\
\hline & Words & WTP1 & WTP2 & Belief & Words & WTP1 & WTP2 & Belief \\
\hline \multirow[t]{2}{*}{ Words } & 1.00 & -0.30 & -0.50 & 0.00 & 1.00 & 0.42 & -0.01 & -0.13 \\
\hline & & 0.266 & 0.047 & 0.987 & 0.107 & & 0.976 & 0.633 \\
\hline \multirow[t]{2}{*}{ WTP1 } & -0.30 & 1.00 & 0.51 & 0.10 & 0.42 & 1.00 & 0.47 & -0.47 \\
\hline & 0.266 & & 0.042 & 0.706 & 0.107 & & 0.069 & 0.069 \\
\hline \multirow[t]{2}{*}{ WTP2 } & -0.50 & 0.51 & 1.00 & 0.13 & -0.01 & 0.47 & 1.00 & -0.13 \\
\hline & 0.047 & 0.042 & & 0.628 & 0.976 & 0.069 & & 0.628 \\
\hline \multirow{4}{*}{ Belief } & 0.00 & 0.10 & 0.13 & 1.00 & -0.13 & -0.47 & -0.13 & 1.00 \\
\hline & 0.987 & 0.706 & 0.628 & & 0.633 & 0.069 & 0.628 & \\
\hline & & Play & & & & & & \\
\hline & Words & WTP1 & WTP2 & Belief & Words & WTP1 & WTP2 & Belief \\
\hline \multirow[t]{2}{*}{ Words } & 1.00 & 0.05 & -0.23 & -0.23 & 1.00 & 0.04 & 0.09 & 0.51 \\
\hline & & 0.862 & 0.397 & 0.399 & & 0.872 & 0.738 & 0.042 \\
\hline \multirow[t]{2}{*}{ WTP1 } & 0.05 & 1.00 & 0.65 & 0.23 & 0.04 & 1.00 & 0.90 & 0.02 \\
\hline & 0.862 & & 0.007 & 0.393 & 0.872 & & $<0.001$ & 0.927 \\
\hline \multirow[t]{2}{*}{ WTP2 } & -0.23 & 0.65 & 1.00 & 0.56 & 0.09 & 0.90 & 1.00 & 0.20 \\
\hline & 0.397 & 0.007 & & 0.024 & 0.738 & $<0.001$ & & 0.468 \\
\hline \multirow{2}{*}{ Belief } & -0.23 & 0.23 & 0.56 & 1.00 & 0.51 & 0.02 & 0.20 & 1.00 \\
\hline & 0.399 & 0.393 & 0.024 & & 0.042 & 0.927 & 0.468 & \\
\hline
\end{tabular}

Note: Pearson's correlation coefficients. P-values for significance presented below coefficients in footnotesize. 
Table C.8: Correlation matrix perception of power variables for chair participants, Experiment 2.

\begin{tabular}{lccccccc}
\hline & \multirow{2}{*}{ WTP1Ch } & WTP1P2 & WTP1P3 & WTP2Ch & WTP2P2 & WTP2P3 & Belief \\
\hline WTP1 Chair & 1 & -0.46 & -0.46 & 0.28 & -0.24 & -0.29 & 0.28 \\
& & 0.040 & 0.040 & 0.231 & 0.307 & 0.212 & 0.228 \\
WTP1 Player 2 & & 1 & 0.72 & -0.25 & 0.67 & 0.42 & 0.19 \\
& & & $<0.001$ & 0.297 & 0.001 & 0.063 & 0.410 \\
WTP1 Player 3 & & 1 & -0.34 & 0.51 & 0.66 & 0.05 \\
& & & 0.144 & 0.021 & 0.001 & 0.824 \\
WTP2 Chair & & & 1 & -0.39 & -0.41 & -0.11 \\
& & & & 0.087 & 0.073 & 0.656 \\
WTP2 Player 2 & & & & 1 & 0.64 & 0.08 \\
& & & & & & 0.002 & 0.731 \\
WTP2 Player 3 & & & & & & & 0.17 \\
& & & & & & & 0.472
\end{tabular}

Neutral-label treatment

\begin{tabular}{lccccccc} 
& WTP1Ch & WTP1P2 & WTP1P3 & WTP2Ch & WTP2P2 & WTP2P3 & Belief \\
\hline WTP1 Chair & 1.00 & -0.42 & -0.52 & -0.17 & 0.03 & 0.42 & 0.24 \\
& & 0.066 & 0.018 & 0.481 & 0.901 & 0.067 & 0.304 \\
WTP1 Player 2 & & 1.00 & 0.24 & 0.25 & 0.43 & -0.46 & 0.03 \\
& & & 0.305 & 0.296 & 0.056 & 0.043 & 0.905 \\
WTP1 Player 3 & & & 1.00 & 0.11 & -0.15 & 0.05 & -0.22 \\
& & & & 0.629 & 0.517 & 0.824 & 0.35 \\
WTP2 Chair & & & & 1.00 & -0.45 & -0.66 & -0.06 \\
& & & & & 0.047 & 0.001 & 0.786 \\
WTP2 Player 2 & & & & & 0.16 & 0.34 \\
WTP2 Player 3 & & & & & & 0.504 & 0.143 \\
& & & & & & 1.00 & 0.06 \\
\end{tabular}

Note: Pearson's correlation coefficients. P-values for significance presented below coefficients in footnotesize. 
Table C.9: Correlation matrix perception of power variables for player 2 participants, Experiment 2.

\begin{tabular}{|c|c|c|c|c|c|c|c|c|c|}
\hline & \multicolumn{9}{|c|}{ Chair-label treatment } \\
\hline & WTP1Ch & WTP1P2 & WTP1P3 & WTP2Ch & WTP2P2 & WTP2P3 & Belief & StatusCh & Adaption motive \\
\hline WTP1 Chair & 1.00 & -0.37 & -0.15 & 0.10 & -0.16 & -0.04 & 0.14 & -0.06 & -0.09 \\
\hline & & 0.103 & 0.521 & 0.685 & 0.510 & 0.861 & 0.548 & 0.803 & 0.717 \\
\hline WTP1 Player 2 & & 1.00 & 0.43 & -0.30 & 0.39 & 0.33 & 0.01 & -0.17 & 0.24 \\
\hline & & & 0.058 & 0.199 & 0.084 & 0.160 & 0.976 & 0.474 & 0.298 \\
\hline WTP1 Player 3 & & & 1.00 & -0.02 & -0.07 & 0.70 & 0.39 & -0.3 & 0.38 \\
\hline & & & & 0.942 & 0.779 & $<0.001$ & 0.088 & 0.196 & 0.095 \\
\hline WTP2 Chair & & & & 1.00 & -0.57 & -0.37 & 0.14 & -0.56 & 0.47 \\
\hline & & & & & 0.009 & 0.105 & 0.552 & 0.009 & 0.034 \\
\hline WTP2 Player 2 & & & & & 1.00 & 0.12 & 0.02 & 0.49 & -0.43 \\
\hline & & & & & & 0.607 & 0.947 & 0.030 & 0.058 \\
\hline WTP2 Player 3 & & & & & & 1.00 & 0.12 & 0.04 & 0.11 \\
\hline & & & & & & & 0.627 & 0.863 & 0.644 \\
\hline Belief & & & & & & & 1.00 & -0.03 & 0.01 \\
\hline & & & & & & & & 0.888 & 0.977 \\
\hline Status Chair & & & & & & & & 1.00 & $\begin{array}{l}-0.74 \\
<0.001\end{array}$ \\
\hline
\end{tabular}

Neutral-label treatment

\begin{tabular}{|c|c|c|c|c|c|c|c|c|c|}
\hline & WTP1Ch & WTP1P2 & WTP1P3 & WTP2Ch & WTP2P2 & WTP2P3 & Belief & StatusCh & Adaption motive \\
\hline WTP1 Chair & 1.00 & -0.38 & -0.23 & 0.20 & 0.30 & -0.21 & 0.09 & -0.16 & 0.40 \\
\hline & & 0.100 & 0.321 & 0.396 & 0.205 & 0.382 & 0.699 & 0.500 & 0.077 \\
\hline WTP1 Player 2 & & 1.00 & 0.32 & -0.32 & 0.36 & 0.18 & 0.10 & 0.25 & -0.28 \\
\hline & & & 0.164 & 0.175 & 0.122 & 0.439 & 0.667 & 0.278 & 0.227 \\
\hline WTP1 Player 3 & & & 1.00 & -0.23 & 0.18 & 0.76 & -0.28 & 0.23 & 0.02 \\
\hline & & & & 0.339 & 0.450 & $<0.001$ & 0.235 & 0.333 & 0.945 \\
\hline WTP2 Chair & & & & 1.00 & -0.63 & -0.33 & 0.02 & -0.79 & 0.48 \\
\hline & & & & & 0.002 & 0.153 & 0.935 & $<0.001$ & 0.033 \\
\hline WTP2 Player 2 & & & & & 1.00 & 0.15 & -0.09 & 0.63 & -0.07 \\
\hline & & & & & & 0.526 & 0.709 & 0.003 & 0.771 \\
\hline WTP2 Player 3 & & & & & & 1.00 & -0.08 & 0.18 & -0.02 \\
\hline & & & & & & & 0.724 & 0.459 & 0.931 \\
\hline Belief & & & & & & & 1.00 & -0.27 & 0.07 \\
\hline & & & & & & & & 0.254 & 0.758 \\
\hline Status Chair & & & & & & & & 1.00 & $\begin{array}{r}-0.59 \\
0.006\end{array}$ \\
\hline
\end{tabular}

Note: Pearson's correlation coefficients. P-values for significance presented below coefficients in footnotesize. 
Table C.10: Correlation matrix perception of power variables for player 3 participants, Experiment 2.

\begin{tabular}{|c|c|c|c|c|c|c|c|c|c|}
\hline & \multicolumn{9}{|c|}{ Chair-label treatment } \\
\hline & WTP1Ch & WTP1P2 & WTP1P3 & WTP2Ch & WTP2P2 & WTP2P3 & Belief & StatusCh & Adaption motive \\
\hline WTP1 Chair & 1.00 & -0.53 & -0.07 & 0.48 & 0.22 & 0.00 & 0.19 & -0.34 & 0.10 \\
\hline & & 0.017 & 0.785 & 0.033 & 0.360 & 1.000 & 0.411 & 0.14 & 0.68 \\
\hline WTP1 Player 2 & & 1.00 & -0.16 & -0.29 & -0.15 & 0.06 & -0.29 & -0.05 & -0.42 \\
\hline & & & 0.508 & 0.210 & 0.535 & 0.790 & 0.212 & 0.835 & 0.065 \\
\hline WTP1 Player 3 & & & 1.00 & -0.03 & 0.06 & 0.07 & 0.47 & 0.30 & 0.19 \\
\hline & & & & 0.912 & 0.810 & 0.775 & 0.035 & 0.192 & 0.420 \\
\hline WTP2 Chair & & & & 1.00 & -0.39 & -0.02 & 0.02 & -0.64 & 0.40 \\
\hline & & & & & 0.089 & 0.934 & 0.926 & 0.003 & 0.080 \\
\hline WTP2 Player 2 & & & & & 1.00 & 0.30 & 0.03 & 0.50 & -0.41 \\
\hline & & & & & & 0.192 & 0.888 & 0.025 & 0.070 \\
\hline WTP2 Player 3 & & & & & & 1.00 & 0.09 & 0.19 & -0.37 \\
\hline & & & & & & & 0.706 & 0.414 & 0.113 \\
\hline Belief & & & & & & & 1.00 & 0.20 & 0.21 \\
\hline Status Chair & & & & & & & & 0.399 & 0.367 \\
\hline Status Chalr & & & & & & & & & $\begin{array}{c}-0.46 \\
0.041\end{array}$ \\
\hline
\end{tabular}

Neutral-label treatment

\begin{tabular}{|c|c|c|c|c|c|c|c|c|c|}
\hline & WTP1Ch & WTP1P2 & WTP1P3 & WTP2Ch & WTP2P2 & WTP2P3 & Belief & StatusCh & Adaption motive \\
\hline WTP1 Chair & 1.00 & 0.01 & -0.22 & 0.26 & 0.53 & -0.30 & -0.13 & -0.17 & 0.24 \\
\hline & & 0.972 & 0.355 & 0.277 & 0.017 & 0.200 & 0.575 & 0.482 & 0.312 \\
\hline WTP1 Player 2 & & 1.00 & 0.47 & 0.41 & 0.05 & 0.06 & 0.17 & -0.14 & 0.48 \\
\hline & & & 0.037 & 0.075 & 0.827 & 0.809 & 0.467 & 0.549 & 0.031 \\
\hline WTP1 Player 3 & & & 1.00 & -0.08 & -0.03 & 0.37 & 0.01 & 0.34 & -0.15 \\
\hline & & & & 0.725 & 0.910 & 0.109 & 0.960 & 0.137 & 0.540 \\
\hline WTP2 Chair & & & & 1.00 & -0.01 & -0.59 & 0.58 & -0.48 & 0.43 \\
\hline & & & & & 0.956 & 0.006 & 0.007 & 0.033 & 0.060 \\
\hline WTP2 Player 2 & & & & & 1.00 & -0.25 & -0.04 & 0.22 & 0.13 \\
\hline & & & & & & 0.286 & 0.868 & 0.353 & 0.579 \\
\hline WTP2 Player 3 & & & & & & 1.00 & -0.46 & 0.29 & -0.42 \\
\hline & & & & & & & 0.041 & 0.211 & 0.067 \\
\hline Belief & & & & & & & 1.00 & -0.14 & 0.30 \\
\hline & & & & & & & & 0.553 & 0.199 \\
\hline Status Chair & & & & & & & & 1.00 & -0.59 \\
\hline
\end{tabular}

Note: Pearson's correlation coefficients. P-values for significance presented below coefficients in footnotesize. 